\title{
Measurement and tailoring of residual stress in expanded austenite on austenitic stainless steel
}

Fernandes, Frederico Augusto Pires; Christiansen, Thomas Lundin; Winther, Grethe; Somers, Marcel A. J.

Published in:

Materials Science and Engineering $A$

Link to article, DOI:

10.1016/j.msea.2017.06.082

Publication date:

2017

Document Version

Peer reviewed version

Link back to DTU Orbit

Citation $(A P A)$ :

Fernandes, F. A. P., Christiansen, T. L., Winther, G., \& Somers, M. A. J. (2017). Measurement and tailoring of residual stress in expanded austenite on austenitic stainless steel. Materials Science and Engineering A, 701, 167-173. https://doi.org/10.1016/j.msea.2017.06.082

\section{General rights}

Copyright and moral rights for the publications made accessible in the public portal are retained by the authors and/or other copyright owners and it is a condition of accessing publications that users recognise and abide by the legal requirements associated with these rights.

- Users may download and print one copy of any publication from the public portal for the purpose of private study or research.

- You may not further distribute the material or use it for any profit-making activity or commercial gain

- You may freely distribute the URL identifying the publication in the public portal 


\title{
Measurement and tailoring of residual stress in expanded austenite on austenitic stainless steel
}

\author{
Frederico A.P. Fernandes ${ }^{\mathrm{i}, \mathrm{ii})}$, Thomas L. Christiansen ${ }^{\mathrm{i})}$, Grethe Winther ${ }^{\mathrm{i})}$, Marcel A.J. Somers ${ }^{\mathrm{i})}$ \\ i) Technical University of Denmark, Produktionstorvet b. 425, 2800 Kgs. Lyngby, Denmark \\ ii) Now with: Federal University of ABC, São Bernardo do Campo, São Paulo, Brazil.
}

\begin{abstract}
Expanded austenite on stainless steel with a high interstitial nitrogen content is characterized by elasto-plastic accommodation of the large composition-induced lattice expansion leading to huge compressive residual stress. The elasto-plastic accommodation as well as the (steep) concentration profile has implications for the measurement strategy to determine lattice strains and associated residual stresses with X-ray diffraction. Lattice strain measurements were performed on nitrided as well as subsequently de-nitrided expanded austenite on AISI 316L stainless steel, for various grazing incidence angles. It is demonstrated that keeping the information depth constant by choosing appropriate combinations of grazing incidence and tilt angle leads to reliable results for the 111 reflection, while the 200 reflection should be avoided. Further, it is shown for the first time that the residual stresses in expanded austenite can be tailored by de-nitriding after nitriding, such that a condition of virtually zero stress at the surface is obtained.
\end{abstract}




\section{Introduction}

Surface engineering of austenitic stainless steel by the conversion of the outer $20-30 \mu \mathrm{m}$ into expanded austenite is achieved by dissolution of a high amount of nitrogen or carbon [1]. Although literature sources on the observation of expanded austenite (as an unwanted corrosion product) can be traced back to as early as 1960, the deliberate exploitation of expanded austenite started in the mid-80ies [2,3].

The case of expanded austenite that develops during dissolution of large quantities of $\mathrm{N}$ or $\mathrm{C}$ from a gaseous, plasma or liquid source, is essentially a diffusion zone in austenite with a concentration gradient in the interstitial atom content and can thus be considered as a graded material. Consequently, also the related properties are varying over the thickness of the case, as for example the magnetic properties [4,5]. Recent, systematic work on homogeneous expanded austenite of uniform composition, i.e. not a layer on a surface, has indeed demonstrated that the dissolution of various quantities of nitrogen in expanded austenite can lead to a transition from para- to ferromagnetic austenite for contents exceeding $\mathrm{y}_{\mathrm{N}}=0.17$ ( $\mathrm{y}_{\mathrm{N}}$ is the occupancy of the lattice of octahedral interstices or, equivalently, the number of $\mathrm{N}$ atoms per metal atom). This magnetic transition is associated with a change in the thermal expansion coefficient of the lattice $[6,7]$. Furthermore, the distribution of nitrogen over the thickness of the expanded austenite zone is associated with a residual stress distribution [8], reaching compressive residual stress of 5-6 GPa. These compressive stresses reduce the solubility of nitrogen in equilibrium with the chemical potential as for example applied by a gas mixture $[9,10]$, while the gradient in residual stress has an effect on the diffusive flux of interstitially dissolved nitrogen and enhances the 
growth rate of the expanded austenite case [10]. Such stress-assisted diffusion combined with the elastic anisotropy of (expanded) austenite, leads to a dependence of the depth of the expanded austenite zone on the grain orientation, which has been experimentally demonstrated earlier [1113]. Furthermore, the enormous lattice expansion introduced by the dissolution of nitrogen is partly accommodated plastically, as was demonstrated from texture changes introduced by lattice rotation [14] and by elastic-plastic modelling [10]. Also, plastic deformation is $h k l$ dependent and was shown to be the origin of anomalous shift of, particularly, the 200 peak to a disproportionate lower Bragg angle in (X-ray) diffraction experiments aiming at revealing the crystal structure of expanded austenite [15]. In various applications the occurrence of a steep gradient in composition and residual stresses could lead to brittle behavior of the case and a modification of these coupled parameters is sought for. In the present work it is demonstrated that the level of interstitially dissolved nitrogen atoms and the associated compressive residual stress level can be tuned by a reduction of the nitrogen content by performing the final stage of the surface engineering treatment in a gas phase with a lower nitrogen activity, leading to socalled de-nitriding.

\section{Experimental}

\subsection{Sample preparation}

AISI 316L discs $\emptyset 20 \mathrm{~mm}$ and $3 \mathrm{~mm}$ in thickness were cut from a supplied bar in hotrolled condition. The chemical composition in wt- $\%$ of the AISI $316 \mathrm{~L}$ steel is given in Table 1. The surface of the specimens was ground and polished at a final stage of $3 \mu \mathrm{m}$ diamond. After polishing the samples were cleaned in ethanol and the initial mass of the samples was measured using an analytical balance with an accuracy of $10 \mu \mathrm{g}$. 
Gaseous nitriding was carried out at $713 \mathrm{~K}\left(440^{\circ} \mathrm{C}\right)$ for $16 \mathrm{~h}$ in a flow of $2 \mathrm{~L} / \mathrm{min}$ of pure ammonia $\left(\mathrm{NH}_{3}\right)$ in a LAC annealing furnace model PKRC 55/09 retrofitted for gaseous nitriding and nitrocarburizing. Activation of the samples to remove the protective oxide layer was carried out in-situ prior to nitriding; all details of this pre-treatment are proprietary. As-nitrided samples were additionally de-nitrided for $2 \mathrm{~h}$ in a tube furnace at $708 \mathrm{~K}\left(435^{\circ} \mathrm{C}\right)$ in flowing $1 \mathrm{~L} / \mathrm{min}$ of hydrogen $\left(\mathrm{H}_{2}\right)$; the de-nitriding temperature was deliberately chosen below the nitriding temperature to avoid case growth and/or chromium nitride precipitation. The mass of the samples was measured after nitriding and after de-nitriding, so nitrogen uptake and withdrawal is obtained per exposed area. From the change in sample mass it was found that $29 \%$ of the nitrogen dissolved during nitriding was removed during de-nitriding.

Cross sections of the nitrided and de-nitrided samples were hot mounted in epoxy resin, ground and polished by standard metallographic procedures for reflected light microscopy in a Zeiss Neophot 30 microscope. Specimens were etched in Kalling's reagent 1 for approximately $15 \mathrm{~s}$ to reveal the microstructural features of the produced layers.

Hardness profiles over the case produced by (de-)nitriding were measured on mounted cross sections with a Future Tech model FM-700 hardness tester applying a load of $5 \mathrm{gf}$ and a dwell time of $5 \mathrm{~s}$.

\subsection{Glow discharge optical emission spectroscopy (GD-OES)}

Composition profiles over the case produced were measured with glow discharge optical emission spectroscopy (GD-OES). The Ar pressure and power to maintain the RF plasma employed for sputtering were $1000 \mathrm{~Pa}$ and $40 \mathrm{~W}$, respectively. For quantification of the profiles a series of certified reference stainless steel samples and a $\mathrm{Fe}_{4} \mathrm{~N}$ layer on iron were used. Unfortunately, no certified samples with known combinations of high nitrogen and moderate 
chromium contents are available. As was recently demonstrated a non-linear relation, a parabolic relation rather than a linear relation applies between N/Cr intensity and N/Cr-content [16]. For this reason a parabolic relation, fitted at 0 and 20 at. $\%\left(\mathrm{Fe}_{4} \mathrm{~N}\right)$, was assumed for quantification of the nitrogen content. The depth was calibrated by measuring the depth of the sputtered crater with a profilometer and assuming a linear sputter rate.

\subsection{X-ray diffraction}

X-ray diffraction experiments were performed using a Bruker AXS D8 diffractometer equipped with a $\mathrm{Cr}$ tube source, using $\mathrm{Cr} \mathrm{K} \alpha$ radiation with wavelength $2.29100 \AA$. The equipment was operated employing a voltage and current of $40 \mathrm{kV}$ and $40 \mathrm{~mA}$, respectively.

For phase analysis a linear focus and Bragg-Brentano symmetrical geometry was applied measuring the diffracted intensity from 40 to $100^{\circ} 2 \theta$ using a step-size of $0.03^{\circ} 2 \theta$ and counting time of $5 \mathrm{~s}$.

For determination of lattice strains, the angular range $50-85^{\circ} 2 \theta$ was measured with a step size of $0.025^{\circ} 2 \theta$. Measurements were performed for the grazing incidence angles $3^{\circ}, 7^{\circ}$ and $12^{\circ}$. For all measurement configurations the $\chi$ angles were $0,25^{\circ}, 38^{\circ}, 49^{\circ}$ and $60^{\circ}$. The measurement configurations correspond to various (effective) $\psi$ angles in the so-called $\sin ^{2} \psi$ method and represent the weighted average over various depth ranges, characterized by the information depth. This will be further addressed in section 3. For peak position determination a cubic background was fitted at the extremities of the scattering angle range and subtracted; subsequently, a (asymmetric) Gaussian function was fitted through the 111 and 200 line profiles, the peak positions of which were taken as Bragg angle in further evaluation of lattice strains. 


\section{Results and interpretation}

\subsection{Metallography and composition}

Micrographs of cross sections of the samples subjected to nitriding and subsequent denitriding are shown in Figure 1. Both as-nitrided (Fig. 1a) and de-nitrided (Fig. 1b) samples show a continuous expanded austenite zone; within experimental accuracy no difference was observed in the zone thickness, which is taken as the average of 20 independent measurements and amounts to $14 \pm 2 \mu \mathrm{m}$ and $13 \pm 1 \mu \mathrm{m}$ for nitrided and de-nitrided samples, respectively. Nevertheless, a slight reduction in thickness of the expanded austenite zone can be expected upon de-nitriding as a consequence of the volume reduction associated with nitrogen removal, i.e. the swelling effect will be less pronounced [17]. The case depths are presented in the hardness profiles in Fig. 1c by the horizontal error bars.

Apparently the hydrogen reduction step to withdraw nitrogen from the produced supersaturated expanded austenite zone by ammonia formation at the sample surface does not influence the optical appearance of the layers. Micro-hardness indentation (Fig.1c) shows that the reduction in nitrogen content in expanded austenite leads to a reduction of the hardness by only about $100 \mathrm{HV}_{0.05}$.

GD-OES profiles obtained after nitriding and after subsequent de-nitriding are shown in Figure 2. Evidently, in the de-nitriding step a major amount of nitrogen can be withdrawn from the expanded austenite zone, such that a plateau of constant nitrogen content corresponding to $\mathrm{Cr}: \mathrm{N}=1: 0.8$ is achieved. The remaining nitrogen is more strongly bound in the sample than in $\mathrm{NH}_{3}$, while the retractable nitrogen is more strongly bound in $\mathrm{NH}_{3}$. This does not necessarily 
imply that the remaining nitrogen is present as $\mathrm{CrN}$ in the sample, but rather short-range order of $\mathrm{Cr}$ and $\mathrm{N}$ occurs [18].

The as-nitrided samples (316L-GN) show a steep nitrogen profile and the surface concentration is roughly twice that obtained after hydrogen reduction. The total amount of nitrogen removed from the concentration profile by de-nitriding is $30 \%$, which is in excellent agreement with the value obtained from the mass reduction of the sample (see section 2.1).

\subsection{X-ray diffractometry}

X-ray diffractograms show that the dissolution of nitrogen in the austenite lattice leads to a shift of the 111 and 200 line profiles to lower Bragg angles (Fig. 3). This shift is a consequence of lattice expansion associated by the dissolution of nitrogen and compressive residual stress. Moreover substantial asymmetric broadening of the line profile is observed, which is likely to be associated with the presence of an in-depth nitrogen-concentration profile (Fig.3). Comparing the 111 peaks for the nitrided and de-nitrided samples shows that broadening remains after denitriding, but that the asymmetry of the 111 peak to the high angle side disappears. Consequently, the asymmetry originates from the nitrogen-concentration profile (Fig. 2), while the broadening that remains after de-nitriding has to be attributed (at least partly) to the strong plastic deformation in the expanded austenite zone as a consequence of the elastic-plastic accommodation of the lattice expansion. A peculiar observation is the observed "splitting" of the 200 reflection after de-nitriding. This was not investigated further, but it was verified that neither $\mathrm{CrN}$ nor $\varepsilon-\mathrm{M}_{2} \mathrm{~N}(\mathrm{M}=\mathrm{Fe}, \mathrm{Cr})$, the most likely candidates for developing during annealing of expanded austenite, can provide an explanation. Instead, the anomalously broad 200 peak, as 
compared to the 111 peak, is ascribed to a larger variation in the elastic strain along 200 after plastic deformation, associated with the elastically more compliant and generally plastically softer response in this direction [19,20]. An immediate implication of the extreme broadening of the 200 line profile (and its $\psi$ dependence) is that this peak is not suitable for lattice strain determination. Consequently, for the nitrided sample the 111 and 200 profiles are used for lattice strain determination, while for the de-nitrided sample only the 111 line profile is used.

\subsection{X-ray lattice strain and stress determination}

X-ray lattice strain/ stress determination is based on probing the lattice strain in a range of crystallites which are differently oriented with respect to the system of principal stresses and relating these lattice strains to the state of stress in the volume probed. Excellent reviews of the technique have been published [21-23]. Essentially, for a flat thermochemically treated surface as in the present case, a rotationally symmetric biaxial state of stress is expected in the plane of the surface, i.e. $\sigma_{11}=\sigma_{22}=\sigma_{\square}$. Then, the lattice strain, $\varepsilon_{\psi}^{h k l}$, experienced in the family of lattice planes $\{h k l\}$ depends on the tilt angle $\psi$ according to:

$$
\varepsilon_{\psi}^{h k l}=\frac{d_{\psi}^{h k l}-d_{\varepsilon=0}^{h k l}}{d_{\varepsilon=0}^{h k l}}=1 / 2 S_{2}^{h k l} \sigma_{\square} \sin ^{2} \psi+2 S_{1}^{h k l} \sigma_{\square}
$$

where $d_{\psi}^{h k l}$ is the lattice spacing for the same $\{h k l\}$ planes in the direction defined by $\psi, d_{\varepsilon=0}^{h k l}$ is

the strain-free lattice spacing and $S_{1}^{h k l}$ and $1 / 2 S_{2}^{h k l}$ are X-ray elastic constants (XECs) depending on the $\{h k l\}$-specific elastic properties of the crystals and their elastic interaction in the sample. 
The strain-free lattice spacing, $d_{\varepsilon=0}^{h k l}$, in Eq. (1) is probed for the so-called strain-free measurement direction, $\psi_{\varepsilon=0}$, which is obtained from equating Eq.(1) to zero and rearranging terms:

$$
\sin ^{2} \psi_{\varepsilon=0}=\frac{-2 S_{1}^{h k l}}{1 / 2 S_{2}^{h k l}}
$$

In an X-ray diffraction experiment the lattice spacing obtained, $\left\langle d_{\psi}^{h k l}\right\rangle$, is the lattice spacing profile weighted over the diffracted intensity:

$\left\langle d_{\psi}^{h k l}\right\rangle=\frac{\int_{0}^{\infty} d_{\psi}^{h k l}(z) \cdot e^{-\mu k_{\psi}^{h l l} z} \cdot d z}{\int_{0}^{\infty} e^{-\mu k_{\psi}^{h k z} z} \cdot d z}$

with $\mu$ the linear absorption coefficient of the applied X-radiation in the phase probed. In Eq. (3) $k_{\psi}^{h k l}$ depends on the diffraction geometry:

- for symmetric diffraction at Bragg angle $2 \theta$ :

$$
k_{\psi}^{h k l}=\frac{2}{\sin \theta \cos \psi}
$$

- for asymmetric diffraction at Bragg angle $2 \theta$ for a fixed incident angle, $\alpha$ :

$$
k_{\psi}^{h k l}=\frac{1}{\cos \chi} \cdot\left(\frac{1}{\sin \alpha}+\frac{1}{\sin (\theta-\alpha)}\right)
$$

where the angles $2 \theta, \alpha$ and $\chi$ are defined in Fig. 4. The rotation angle $\chi$ is related to the tilt angle, $\psi$, by:

$\cos \psi=\cos \chi \cdot \cos (\theta-\alpha)$

The information depth, $\tau_{\psi}^{h k l}$, is the diffraction-weighted average depth, $\left\langle z_{\psi}^{h k l}\right\rangle$ : 


$$
\tau_{\psi}^{h k l}=\left\langle z_{\psi}^{h k l}\right\rangle=\frac{\int_{0}^{\infty} z \cdot e^{-\mu k_{\psi}^{h k l} z} \cdot d z}{\int_{0}^{\infty} e^{-\mu k_{\psi}^{h k l} z} \cdot d z}=\frac{1}{\mu k_{\psi}^{h k l}}
$$

For a layer of thickness, $t$, the information depth becomes:

$$
\tau_{\psi}^{h k l}=\left\langle z_{\psi}^{h k l}\right\rangle=\frac{\int_{0}^{t} z \cdot e^{-\mu k_{\psi}^{h l} z} \cdot d z}{\int_{0}^{t} e^{-\mu k_{\psi}^{h l} z} \cdot d z}=\frac{1}{\mu k_{\psi}^{h k l}}+\frac{t \cdot e^{-\mu k_{\psi}^{h k t} t}}{e^{-\mu k k_{\psi} t}-1}
$$

Arbitrarily $\left\langle d_{\psi}^{h k l}\right\rangle$ could be, and often is, assigned to $\tau_{\psi}^{h k l}$. However, it can be straightforwardly demonstrated that such a relation between $\left\langle d_{\psi}^{h k l}\right\rangle$ and $\tau_{\psi}^{h k l}$ only applies if the lattice spacing depends linearly on depth [24]. Below the results obtained by asymmetric (grazing incidence) Xray diffraction are presented.

Asymmetric, grazing incidence diffraction geometry

The dependence of the lattice parameter, $\left\langle a_{\psi}^{h k l}\right\rangle$, as derived from the lattice spacings $\left\langle d_{\psi}^{111}\right\rangle$ and $\left\langle d_{\psi}^{200}\right\rangle$ (for the de-nitrided sample only $\left\langle d_{\psi}^{111}\right\rangle$ ) with the effective tilt angle (cf. Eq. (5)), $\psi$, in the asymmetric diffraction configuration is shown in Fig. 5a for the three applied grazing incidence angles. The corresponding information depths as calculated according to Eq. (6b) for average values of the Bragg angles corresponding with 111 and 200 reflections as well as for the actual combinations of experimental tilt and Bragg angles are presented in Fig. 5b. In the calculations the linear absorption coefficient of $\mathrm{Cr} \mathrm{K}_{\alpha}$ radiation in expanded austenite was taken as 0.0926 
$\mu \mathrm{m}^{-1}$. The $\left\langle a_{\psi}^{h k l}\right\rangle$ vs. $\sin ^{2} \psi$ relations in Fig. 5a clearly demonstrate that for the as-nitrided sample strong compressive stresses are present, while for the subsequently de-nitrided sample the stresses have (largely) relaxed. The difference in slope for lattice parameters determined for 111 and 200 reflections shows that the lattice spacing measured in the $<200>$ direction is more sensitive for stress than those measured in the <111> direction, implying that in Eq. (1) $1 / 2 S_{2}^{200}>1 / 2 S_{2}^{111}$, consistent with previous work [8,25] and recently qualitatively explained from non-linear elastic behavior of plastically deformed expanded austenite [15]. The variation of the information depth with $\sin ^{2} \psi$ indicates that the lattice parameters in Fig. 5a are the effective average over different depth ranges and thus over different concentration ranges for the asnitrided sample (cf. Fig. 2). Consequently, stress values for the as-nitrided sample determined straightforwardly from the slopes of $\left\langle a_{\psi}^{111}\right\rangle$ and $\left\langle a_{\psi}^{200}\right\rangle$ in Fig. 5a will be affected by a ghost stress artefact, i.e. fictitious stresses arising as a consequence of a variation with tilt angle of the effective depth where the measured lattice spacing applies and a lattice spacing profile as a consequence of a composition and/or a stress-depth profile (see also [8,24]). Ghost-stress effects arising from a composition-depth profile will be virtually absent for the de-nitrided sample, because here the composition appears independent of depth (Fig. 2); ghost stress effects arising from stress gradients only are generally limited [24] as was also shown for the case of expanded austenite zones [8]. Consistent with a variation of the information depth (Fig. 5b) with a variation in incident angle, and the falling nitrogen concentration with depth (Fig. 2), the $\left\langle a_{\psi}^{h k l}\right\rangle$ vs. $\sin ^{2} \psi$ relations are shifted to lower $\left\langle a_{\psi}^{h k l}\right\rangle$ values with increasing grazing incidence angle, $\alpha$. For the de-nitrided sample, an important reduction in the slope and intercept of the $\left\langle a_{\psi}^{h k l}\right\rangle$ vs. 
$\sin ^{2} \psi$ relation is observed as compared to the nitrided sample. Now, consistent with the absence of a nitrogen concentration gradient within the probed volume (Fig. 2), the $\left\langle a_{\psi}^{111}\right\rangle$ values for the denitrided sample largely overlap for the three incident angles $3^{\circ}, 7^{\circ}$ and $12^{\circ}$. Even though the variation in information depth under grazing incidence diffraction conditions is limited (cf. Fig. $5 b)$, the information depth at the highest tilt angle is $50 \%$ of that at the lowest tilt angle. As illustrated by the horizontal dashed line at $\tau_{\psi}=0.5 \mu \mathrm{m}$, a combination of the 3 applied grazing incidence angles, $\alpha$, and the appropriate effective tilt angles, $\psi$, enables to keep the information depth constant. Note that this does not guarantee that also the values for $\left\langle a_{\psi}^{h k l}\right\rangle$ apply at the same depth for the various $\psi$-directions, because such a correspondence is only expected for a linear lattice spacing profile [24]. The lattice parameters at $\tau_{\psi}=0.5 \mu \mathrm{m}$ as interpolated among the data in Fig. 5a for the chosen $\psi$ angles are given for 111 and 200 reflections in Fig. 6.

\section{Discussion}

\subsection{Residual stress and composition in expanded austenite}

From the relations between $\left\langle a_{\psi}^{h k l}\right\rangle$ and $\sin ^{2} \psi$ given in Figs. 5a and 6 the intercept, $\left\langle a_{\psi=0}\right\rangle$, and slope, $\Delta\left\langle a_{\psi}^{h k l}\right\rangle / \Delta \sin ^{2} \psi$, were obtained by linear regression. These values were applied to obtain the strain-free lattice parameter, $\left\langle a_{\varepsilon=0}\right\rangle$, nitrogen content, $y_{N}$, and residual stress, $\sigma_{\square}$. For this purpose (cf. Eqs. (1) and (2)), the X-ray elastic constants were taken as for $\mathrm{Fe}-12 \% \mathrm{Cr}-12 \% \mathrm{Ni}$ [26], applying the Kröner-Eshelby grain interaction model (see [8,24]). The nitrogen content was obtained from the relations between (strain-free) lattice parameter and interstitial content for 
nitrogen-stabilized and carbon-stabilized expanded austenite [27]. For the nitrided sample only the relation for nitrogen-stabilized expanded austenite is considered, while for the de-nitrided sample both relations were taken into account, recognizing the relation for nitrogen- and carbon stabilized expanded austenite represent ferro-magnetic and para-magnetic $\gamma_{\mathrm{N}}$, respectively [7]. For the nitrided and de-nitrided sample, all results obtained for $y_{N}$ (the occupancy of the lattice of octahedral interstices) and $\sigma_{\square}$ are presented in Table 2. For the de-nitrided sample differentiation is made between para-magnetic $(\mathrm{pm})$ and ferro-magnetic $(\mathrm{fm})$ expanded austenite.

There appears to be a systematic discrepancy between $y_{N}$ values derived from the lattice parameters obtained from 111 and 200 reflections, such that $y_{N}$ obtained from 200 is systematically higher (Fig. 7a). This is consistent with previous investigations, which showed that the 200 reflection is more sensitive than the 111 reflection for changes in composition/stress. As was pointed out the XECs in expanded austenite are unknown and likely depend on the nitrogen content in expanded austenite. Furthermore, analogous to austenite and as a consequence of elastic anisotropy, plastic deformation as occurring in the expanded austenite zone during its growth into austenite, will lead to $h \mathrm{kl}$ dependent non-linear stress-strain behavior. In general in-plane equi-biaxial compression is comparable to out-of-plane uniaxial tension as the stress states differ by a hydrostatic pressure only. If effects of the free sample surface can be ignored, results for conventional mechanical uniaxial tension may therefore be used as reference to explain the different interactions along 111 and 200. As indicated by self-consistent elastoplastic models [18], 200 reflections along the tensile direction for a stainless steel comparable to the present exhibit more elastic strain than other reflections, which has also been experimentally confirmed to hold on average at the grain scale [28]. For 200 reflections perpendicular to the 
tensile axis, elasto-plastic simulations reveal much smaller elastic contractions than for other reflections, which is attributed to plastically anisotropic contraction of grains of certain orientations $[19,20]$. In the context of the present experiments, these results imply that the 200 reflection from elasto-plastically deformed samples deviates substantially from the purely elastic case. The 111 reflection is much less affected by the plastic response and is therefore the focus of the remainder of this paper. In agreement with experimental findings for elastic uniaxial tension [28], a grain interaction model (GIM) in-between the extremes of Reuss and Voigt is selected, in this case the Kröner-Eshelby elastic GIM. This does not necessarily imply that this combination of $h k l$ and GIM is preferred to obtain quantitatively correct stress values in expanded austenite, because so far the elastic constants remain unknown.

Comparison of the nitrogen contents derived from the strain free lattice parameter for 111 with the nitrogen content as determined with GD-OES (Fig. 2) shows very good correspondence for the nitrided sample, while for the de-nitrided sample good correspondence is obtained for the para-magnetic lattice dependence on interstitial content.

The stress values derived from lattice strains measured for 111 reflections and the KrönerEshelby GIM are presented in Fig. $7 \mathrm{~b}$ as a function of the applicable information depth. For the nitrided sample the stresses obtained at 3 different grazing incidence angles increase with information depth. As followed from the $\left\langle a_{\psi}^{h k l}\right\rangle$ vs. $\sin ^{2} \psi$ graph in Fig.5a and $\mathrm{y}_{\mathrm{N}}$ in Fig.7a the nitrogen content in this region falls with depth giving rise to ghost stress effects, which would lead to an additional tensile stress value as compared to the actual stress. The additional tensile stress will be larger for a larger variation in information depth (cf. Fig. 5b). Hence, the compressive stress decreases with increasing information depth for the three grazing incidence 
angles. Indeed, correcting for the variation in information depth with tilt, by keeping the information depth constant, leads to a more negative stress value of about -5 GPa. For the 200 reflection the residual stress values are systematically less compressive than those obtained from the 111 reflection (Table 2) and, consistently with 111, a larger compressive stress value is obtained for a constant information depth. From the lattice strains probed for the (200) lattice planes the obtained stress values appear to be up to $15 \%$ smaller (in absolute value) than those derived from the lattice strain probed for the (111) lattice planes (Table 2). In this respect it is mentioned that the $h k l$ dependence of the XECs is unknown. Therefore this difference between stress derived from 111 and 200 reflections is considered a good correspondence.

For the de-nitrided sample compressive stress is observed to be largely independent of the grazing incidence angle. For the constant information depth of $0.5 \mu \mathrm{m}$ the de-nitrided sample yields virtually zero stress. The difference between stress values for constant grazing incidence angle and varying grazing incidence angle for constant information depth cannot be explained from a concentration gradient (cf. Fig. 2).

\subsection{Implications for industrial application}

The present results show that an expanded austenite zone in its as-grown state has huge compressive elastic residual stresses which are largely composition-induced, consistent with previous investigations. Upon de-nitriding these elastic stresses relax to a virtually unstressed state, despite the presence of a substantial amount of nitrogen in the expanded austenite zone. 
The reason for elastic relaxation of the compressive residual stresses in the expanded austenite zone after de-nitriding is that an appreciable part of the lattice expansion associated with nitrogen dissolution is accommodated plastically during growth of the expanded austenite zone into the original austenite. The observed splitting of the 200 peak of the de-nitrided sample is evidence of the complexity of this relaxation.

Nitriding at a low nitriding potential to achieve the relatively low nitrogen content as obtained after de-nitriding (cf. Fig. 2) is anticipated to give an expanded austenite case different from the one achieved here by nitriding and subsequent de-nitriding. Firstly, the growth rate will be reduced importantly, due the smaller diffusive flux as a consequence of the shallower concentration profile and the smaller (concentration dependent) diffusion coefficient of nitrogen (cf. $[9,10,27])$. Secondly, the extent of plastic deformation in expanded austenite will be limited [10]. Nevertheless, the level of elastic residual stress (close to the surface) will be high, because the elastic accommodation of the lattice expansion is still present.

The notion that elastic compressive stresses can be released by removing nitrogen from solid solution implies that the level of elastic residual stress in expanded austenite can in principle be adjusted after growth of the case, by inserting the appropriate level of dissolved nitrogen in a controlled atmosphere with known nitrogen activity in the final stage of the thermochemical treatment. Such after-treatment can also be of practical use for adjusting magnetic properties, because the de-nitrided condition is paramagnetic. Reducing the nitrogen content to below the threshold level $\left(\mathrm{y}_{\mathrm{N}}=0.17\right)$ where expanded austenite becomes ferro-magnetic can be beneficial. For example, in components where wear plays a role, so that no debris is accumulated, because of magnetic attraction. 


\section{Conclusions}

The present work demonstrates that the choice of $h k l$ for residual stress analysis in expanded austenite is of paramount importance. The 200 line profile is not a good choice for the elastically and plastically anisotropic expanded austenite with remaining plastic deformation.

Even for the shallow information depths obtained by grazing incidence X-ray diffraction ghost stress effects in a (steep) lattice parameter profile, arising from a variation of information depth with tilt angle may play a role of importance. A combination of grazing incidence angles to keep the information depth constant with tilt angle appears to be a pragmatic solution.

De-nitriding of expanded austenite can be applied to vary the nitrogen content in the expanded austenite zone and tune the residual stress level at the surface. De-nitriding has a modest effect on the hardness profile.

\section{Acknowledgement}

Frederico A.P. Fernandes is grateful to the CNPq Brazilian council for the scholarship granted under the process number 201858/2011-8.

\section{References}

[1] M.A.J. Somers, T.L. Christiansen, in Thermochemical Surface Engineering, WoodHead Publishing, ISBN 978-0-85709-592-3, 2015, 555-579.

[2] B. Kolster, VDI-Berichte 506 (1983) 107-113.

[3] L.Z. Zhang, T. Bell, Surf. Eng. 1 (1985) 131-136. 
[4] M.P. Fewell, D.R.G. Mitchell, J.M. Priest, K.T. Short, G.A. Collins, Surf. Coatings Techn. 131 (2000) 300-306.

[5] R.L.O Basso, V.L. Pimentel, S. Weber, G. Marcos, T. Czerwiec, I.J.R. Baumvol, C.A. Figueroa, J. Appl. Phys, 105 (2009) 124914

[6] B. Brink, K. Ståhl, T.L. Christiansen, M.A.J. Somers, J. Appl. Cryst., 47 [2014), 819-826.

[7] B.K. Brink, K. Ståhl, T.L. Christiansen, C. Frandsen, M.F. Hansen, M.A.J. Somers, Acta Mater., 106, 2016, 32-39.

[8] F.A.P. Fernandes, T.L. Christiansen, G. Winther, M.A.J. Somers, Acta Mater. 94 (2015) 271-280.

[9] T.L. Christiansen, K.V. Dahl, M.A.J. Somers, Mater. Sci. Techn. 24 (2008) 159-167.

[10]F.N. Jespersen, J.H. Hattel, M.A.J. Somers, Model. Sim. Mater. Sci. Eng. 24 (2016) 025003 (31p)

[11]H. He, T. Czerwiec, C.Dong, H. Michel, Surf. Coatings Techn. 163-164 (2003) 331-338.

[12] A. Martinavičius, G. Abrasonis, W. Möller, J. Appl. Phys. 110 (2011) 074907.

[13]D. Wu, H. Kahn, J.C. Dalton, G.M. Michal, F. Ernst, A.H. Heuer, Acta Mater. 79 (2014) 339-350.

[14]C. Templier, J.C. Stinville, P. Villechaisse, P.O. Renault, G. Abrasonis, J.P. Rivière, A. Martinavičius, M. Drouet, Surf. Coatings Techn. 204 (2010) 2551-2558.

[15]B.K. Brink, K. Ståhl, T.L. Christiansen, J. Oddershede, G. Winther, M.A.J. Somers, Scr. Mater. 117 (2017) 59-62.

[16] S. Baunack, V. Hoffmann, W. Zahn, Microchim. Acta, 156 (2006) 69-72.

[17] J.C. Stinville, C. Templier, P. Villlechaisse, L. Pichon, J. Mater. Sci. 46 (2011) 5503-5511.

[18] J. Oddershede, T.L. Christiansen, K. Ståhl, M.A.J. Somers, Scr. Mater. 62 (2010) 290-293. 
[19]B. Clausen, T. Lorentzen, T. Leffers, Acta Mater. 46 (1998) 3087-3098.

[20]D.-F. Li, N.P. O’Dowd, J. Mech. Phys. Solids 59 (2011) 2421-2441.

[21] V. Hauk, "Structural and Residual Stress Analysis by Non-Destructive Methods: Evaluation - Application - Assessment”, Elsevier Science, 1997.

[22] A. Pyzalla, H. Berns, Mat.-wiss. U. Werkstofftech. 24 (1997) 180-197.

[23]P.J. Withers, H.K.D.H. Bhadeshia, Mater. Sci. Tech., 17 (2001) 355-365.

[24] T.L. Christiansen, M.A.J. Somers, Mater. Sci. Eng. A, 424 (2006) 181-189.

[25]F. Bottoli, T.L. Christiansen, G. Winther, M.A.J. Somers, Metall. Mater. Trans. A, 47 (2016) 4001-4011.

[26]F. Bollenrath, V. Hauk, E. Müller, Z. Metallkd. 58 (1967) 76-82.

[27] T.L. Christiansen, M.A.J. Somers, Int. J. Mater. Res. Former. Zeitschrift Fuer Met. 100 (2009) 1361-1377.

[28] N.Y. Juul, G. Winther, D. Dale, M.K.A. Koker, P. Shade, J. Oddershede, Scr. Mater., 120 (2016) 1-4. 


\title{
Measurement and tailoring of residual stress in expanded austenite on austenitic stainless steel
}

Frederico A.P. Fernandes ${ }^{\mathrm{i}, \mathrm{ii})}$, Thomas L. Christiansen ${ }^{\mathrm{i})}$, Grethe Winther ${ }^{\mathrm{i})}$, Marcel A.J. Somers ${ }^{\mathrm{i})}$

i) Technical University of Denmark, Produktionstorvet b. 425, 2800 Kgs. Lyngby, Denmark

ii) Now with: Federal University of ABC, São Bernardo do Campo, São Paulo, Brazil.

\begin{abstract}
Expanded austenite on stainless steel with a high interstitial nitrogen content is characterized by elasto-plastic accommodation of the large composition-induced lattice expansion leading to huge compressive residual stress. The elasto-plastic accommodation as well as the (steep) concentration profile has implications for the measurement strategy to determine lattice strains and associated residual stresses with X-ray diffraction. Lattice strain measurements were performed on nitrided as well as subsequently de-nitrided expanded austenite on AISI 316L stainless steel, for various grazing incidence angles. It is demonstrated that keeping the information depth constant by choosing appropriate combinations of grazing incidence and tilt angle leads to reliable results for the 111 reflection, while the 200 reflection should be avoided. Further, it is shown for the first time that the residual stresses in expanded austenite can be tailored by de-nitriding after nitriding, such that a condition of virtually zero stress at the surface is obtained.
\end{abstract}




\section{Introduction}

Surface engineering of austenitic stainless steel by the conversion of the outer 20-30 $\mu \mathrm{m}$ into expanded austenite is achieved by dissolution of a high amount of nitrogen or carbon [1]. Although literature sources on the observation of expanded austenite (as an unwanted corrosion product) can be traced back to as early as 1960, the deliberate exploitation of expanded austenite started in the mid-80ies [2,3].

The case of expanded austenite that develops during dissolution of large quantities of $\mathrm{N}$ or $\mathrm{C}$ from a gaseous, plasma or liquid source, is essentially a diffusion zone in austenite with a concentration gradient in the interstitial atom content and can thus be considered as a graded material. Consequently, also the related properties are varying over the thickness of the case, as for example the magnetic properties [4,5]. Recent, systematic work on homogeneous expanded austenite of uniform composition, i.e. not a layer on a surface, has indeed demonstrated that the dissolution of various quantities of nitrogen in expanded austenite can lead to a transition from para- to ferromagnetic austenite for contents exceeding $\mathrm{y}_{\underline{N}}=0.17$ ( $\underline{\mathrm{V}_{\mathrm{N}}}$ is the occupancy of the lattice of octahedral interstices or, equivalently, the number of $\mathrm{N}$ atoms per metal atom). This magnetic transitionand is associated with a change in the thermal expansion coefficient of the lattice [6,7]. Furthermore, the distribution of nitrogen over the thickness of the expanded austenite zone is associated with a residual stress distribution [8], reaching compressive residual stress of 5-6 GPa. These compressive stresses reduce the solubility of nitrogen in equilibrium with the chemical potential as for example applied by a gas mixture $[9,10]$, while the gradient in residual stress has an effect on the diffusion-diffusive flux of interstitially dissolved nitrogen and 
enhances the growth rate of the expanded austenite case [10]. Such stress-assisted diffusion combined with the elastic anisotropy of (expanded) austenite, leads to a hkl-dependent dependence of the depth of the expanded austenite zone on the grain orientation, which has been experimentally demonstrated earlier [11-13]. Furthermore, the enormous lattice expansion introduced by the dissolution of nitrogen is partly accommodated plastically, as was demonstrated from texture changes introduced by lattice rotation [14] and by elastic-plastic modelling [10]. Also, plastic deformation is $h k l$ dependent and was recently-shown to be the origin forof anomalous shift of, particularly, the 200 peak to a disproportionate anomalously lower Bragg angles in (X-ray) diffraction experiments aiming at revealing the crystal structure of expanded austenite [15]. In various applications the occurrence of a steep gradient in composition and residual stresses could lead to brittle behavior of the case and a modification of these coupled parameters is sought for. In the present work it is demonstrated that the level of interstitially dissolved nitrogen atoms and the associated compressive residual stress level can be tuned by removal of part a reduction of the nitrogen atoms-content by subjecting-performing the final stage of the surface engineering treatment in a gas phase with a lower nitrogen activity, leading to so-called de-nitriding.

\section{Experimental}

\subsection{Sample preparation}

AISI 316L discs Ø 20_mm and 3_mm in thickness were cut from the-a supplied bar in hotrolled condition. The chemical composition in wt-\% of the AISI 316L steel is given in Table 1. The material was as supplied in a hot rolled condition. The surface of the specimens was ground and polished at a final stage of $3 \_\mu m$ diamond. After polishing the samples were cleaned in 
ethanol and the initial mass of the samples was measured using an analytical balance with an accuracy of $10 \mu \mathrm{g}$.

Gaseous nitriding was carried out at $713 \mathrm{~K}\left(440^{\circ} \mathrm{C}\right)$ for $16 \mathrm{~h}$ in a flow of $2 \_\mathrm{t} / \mathrm{min}$ of pure ammonia $\left(\mathrm{NH}_{3}\right)$ in a LAC annealing furnace model PKRC 55/09 retrofitted for gaseous nitriding and nitrocarburizing. Activation of the samples to remove the protective oxide layer was carried out in-situ prior to nitriding; all details of this pre-treatment are proprietary. As-nitrided samples

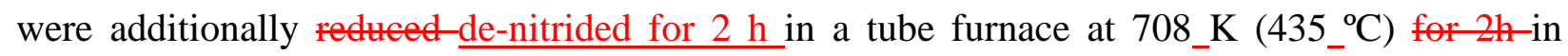
flowing 1_tL/min of hydrogen $\left(\mathrm{H}_{2}\right)$; the de-nitriding temperature was deliberately chosen below the nitriding temperature to avoid case growth and/or chromium nitride precipitation. The mass of the samples was also-measured after nitriding and hydrogen reduction (after de-nitriding), so nitrogen uptake and withdrawal is obtained per exposed area. From the change in sample mass it was found that During de-nitriding 29_\% of the nitrogen dissolved during nitriding was retractedremoved during de-nitriding.

Cross sections of the nitrided and de-nitrided samples were hot mounted in epoxy resin, ground and polished by standard metallographic procedures for subsequent-reflected light microscopy in a Zeiss Neophot 30 microscope. All Sspecimens were etched in Kalling's reagent 1 for approximately 15s to reveal the microstructural features of the produced layers.

Hardness profiles over the case produced by (de-)nitriding were measured on mounted cross sections with a Future Tech model FM-700 hardness tester applying a load of 5_gf and a dwell time of 5_s.

\subsection{Glow discharge optical emission spectroscopy (GD-OES)}

Composition profiles over the case produced were measured with glow discharge optical emission spectroscopy (GD-OES). The Ar pressure and power to maintain the RF plasma 
employed for sputtering were $1000 \mathrm{~Pa}$ and $40 \mathrm{~W}$, respectively. For quantification of the profiles a series of certified reference stainless steel samples and a $\mathrm{Fe}_{4} \mathrm{~N}$ layer on iron were used. Unfortunately, no certified samples with known combinations of high nitrogen and moderate chromium contents are available. As was recently demonstrated a non-linear relation, but rather-a parabolic relation rather than a linear relation applies between $\mathrm{N} / \mathrm{Cr}$ intensity and $\mathrm{N} / \mathrm{Cr}$-content [16]. For this reason a parabolic relation, fitted at 0 and 20 at. $\%\left(\mathrm{Fe}_{4} \mathrm{~N}\right)_{2}$ was assumed for quantification of the nitrogen content. The depth was calibrated by measuring the depth of the sputtered crater with a profilometer and assuming a linear sputter rate.

\subsection{X-ray diffraction}

X-ray diffraction experiments were performed using a Bruker AXS D8 diffractometer equipped with a $\mathrm{Cr}$ tube source, using $\mathrm{Cr} \mathrm{K} \alpha$ radiation with wavelength $2.29100 \AA$. The equipment was operated employing a voltage and current of $40 \mathrm{kV}$ and $40 \mathrm{~mA}$, respectively.

For phase analysis a linear focus and Bragg-Brentano symmetrical geometry was applied measuring the diffracted intensity from 40 to $100{ }^{\circ} 2 \theta$ using a step-size of $0.03^{\circ} 2 \theta$ and counting time of $5 \mathrm{~s}$.

For determination of lattice strains, the angular range 50-85 ${ }^{\circ} 2 \theta$ was measured with a step size of $0.025^{\circ} 2 \theta$. Measurements were performed for the grazing incidence angles $3^{\circ}, 7^{\circ}$ and $12^{\circ}$. For all measurement configurations the $\chi$ angles were $0,25^{\circ}, 38^{\circ}, 49^{\circ}$ and $60^{\circ}$. The measurement configurations correspond to various (effective) $\psi$ angles in the so-called $\sin ^{2} \psi$ method and represent the weighted average over various depth ranges, characterized by the information depth. This will be further addressed in section 3. For peak position determination a cubic background was fitted at the extremities of the scattering angle range and subtracted; 
subsequently, a (asymmetric) Gaussian function was fitted through the 111 and 200 line profiles, the peak positions of which were taken as Bragg angle in further evaluation of lattice strains.

\section{Results and interpretation}

\subsection{Metallography and composition}

Micrographs of cross sections of the samples subjected to nitriding and subsequent denitriding are shown în Figure 1. Both as-nitrided (Fig. 1a) and de-nitrided (Fig. 1b) samples show a continuous expanded austenite zone; within experimental accuracy no difference was observed in the zone thickness, which is taken as the average of 20 independent measurements and amounts to $14 \pm 2 \mu \mathrm{m}$ and $13 \pm 1 \mu \mathrm{m}$ for nitrided and de-nitrided samples, respectively. Nevertheless, a slight reduction in thickness of the expanded austenite zone can be expected upon de-nitriding as a consequence of the volume reduction associated with nitrogen removal, i.e. the swelling effect will be less pronounced [17]. The case depths are presented in the hardness profiles in Fig. 1c by the horizontal error bars.

Apparently the hydrogen reduction step to withdraw nitrogen from the produced supersaturated expanded austenite zone by ammonia formation at the sample surface does not influence the optical appearance of the layers. Micro-hardness indentation (Fig.1c) shows that the reduction in nitrogen content in expanded austenite leads to a reduction of the hardness by only about $100 \mathrm{HV}_{0.05}$.

GD-OES profiles obtained after nitriding and after subsequent de-nitriding are shown in Figure 2. Evidently, in the de-nitriding step a major amount of nitrogen can be retracted 
withdrawn from the expanded austenite zone, such that a plateau of constant nitrogen content corresponding to $\mathrm{Cr}: \mathrm{N}=1: 0.8$ is achieved. The remaining nitrogen is more strongly bound in the sample than in $\mathrm{NH}_{3}$, while the retractable nitrogen is more strongly bound in $\mathrm{NH}_{3}$. This does not necessarily imply that the remaining nitrogen is present as $\mathrm{CrN}$ in the sample, but rather shortrange order of Cr and $\mathrm{N}$ occurs [18].

The as-nitrided samples (316L-GN) show a steep nitrogen profile and the surface concentration is roughly twice that obtained after hydrogen reduction. The total amount of nitrogen removed from the concentration profile by de-nitriding is $30 \%$, which is in excellent agreement with the value obtained from the mass reduction of the sample (see section above 2.1 ).

\subsection{X-ray diffractometry}

X-ray diffractograms show that the dissolution of nitrogen in the austenite lattice leads to a shift of the 111 and 200 line profiles to lower Bragg angles_(Fig. 3). This shift is a consequence of lattice expansion associated by the dissolution of nitrogen and compressive residual stress. Moreover substantial asymmetric broadening of the line profile is observed, which is likely to be associated with the presence of an in-depth nitrogen-concentration profile (Fig.3). Comparing the 111 peaks for the nitrided and de-nitrided samples shows that broadening remains after denitriding, but that the asymmetry of the 111 peak to the high angle side disappears. Consequently, the asymmetry originates from the nitrogen-concentration profile (Fig. 2), while the broadening that remains after de-nitriding has to be attributed (at least partly) to the strong plastic deformation in the expanded austenite zone as a consequence of the elastic-plastic accommodation of the lattice expansion. A peculiar observation is the observed "splitting" of the 
200 reflection after de-nitriding. This was not investigated further, but it was verified that neither CrN nor $\varepsilon-\mathrm{M}_{2} \mathrm{~N}(\mathrm{M}=\mathrm{Fe}, \mathrm{Cr})$, the most likely candidates for developing during annealing of expanded austenite, can provide an explanation. Instead, the_anomalously broad 200 peak, as compared to the 111 peak, is ascribed to a larger variation in the elastic strain along 200 after plastic deformation, associated with the elastically more compliant and generally plastically softer response in this direction $[19,20]$. An immediate implication of the extreme broadening of the 200 line profile (and its $\psi$ dependence) is that this peak is not suitable for lattice strain determination. Consequently, for the nitrided sample the 111 and 200 profiles are used for lattice strain determination, while for the de-nitrided sample only the 111 line profile is used.

\subsection{X-ray lattice strain and stress determination}

$\mathrm{X}$-ray lattice strain/ stress determination is based on probing the lattice strain in a range of crystallites which are differently oriented with respect to the system of principal stresses and relating these lattice strains to the state of stress in the volume probed. Excellent reviews of the technique have been published [21-23]. Essentially, for a flat thermochemically treated surface as in the present case, a rotationally symmetric biaxial state of stress is expected in the plane of the surface, i.e. $\sigma_{11}=\sigma_{22}=\sigma_{\|}$. Then, the lattice strain, $\varepsilon_{\psi}^{h k l}$, experienced in the family of lattice planes $\{h k l\}$ depends on the tilt angle $\psi$ according to:

$$
\varepsilon_{\psi}^{h k l}=\frac{d_{\psi}^{h k l}-d_{\varepsilon=0}^{h k l}}{d_{\varepsilon=0}^{h k l}}=1 / 2 S_{2}^{h k l} \sigma_{\|} \sin ^{2} \psi+2 S_{1}^{h k l} \sigma_{\|}
$$


where $d_{\psi}^{h k l}$ is the lattice spacing for the same $\{h k l\}$ planes in the direction defined by $\psi, d_{\varepsilon=0}^{h k l}$ is the strain-free lattice spacing and $S_{1}^{h k l}$ and $1 / 2 S_{2}^{h k l}$ are X-ray elastic constants (XECs) depending on the $\{h k l\}$-specific elastic properties of the crystals and their elastic interaction in the sample. The strain-free lattice spacing, $d_{\varepsilon=0}^{h k l}$, in Eq. (1) is probed for the so-called strain-free measurement direction, $\psi_{\varepsilon=0}$, which is obtained from equating Eq.(1) to zero and rearranging terms:

$$
\sin ^{2} \psi_{\varepsilon=0}=\frac{-2 S_{1}^{h k l}}{1 / 2 S_{2}^{h k l}} .
$$

In an X-ray diffraction experiment the lattice spacing obtained, $\left\langle d_{\psi}^{h k l}\right\rangle$, is the lattice spacing profile weighted over the diffracted intensity:

$\left\langle d_{\psi}^{h k l}\right\rangle=\frac{\int_{0}^{\infty} d_{\psi}^{h k l}(z) \cdot e^{-\mu k_{\psi}^{h k l} z} \cdot d z}{\int_{0}^{\infty} e^{-\mu k_{\psi}^{h k l} z} \cdot d z}$

with $\mu$ the linear absorption coefficient of the applied X-radiation in the phase probed. In Eq. (3) $k_{\psi}^{h k l}$ depends on the diffraction geometry:

- $\quad$ for symmetric diffraction at Bragg angle $2 \theta$ :

$$
k_{\psi}^{h k l}=\frac{2}{\sin \theta \cos \psi}
$$

- $\quad$ for asymmetric diffraction at Bragg angle $2 \theta$ for a fixed incident angle, $\alpha$ :

$$
k_{\psi}^{h k l}=\frac{1}{\cos \chi} \cdot\left(\frac{1}{\sin \alpha}+\frac{1}{\sin (\theta-\alpha)}\right)
$$


where the angles $2 \theta, \alpha$ and $\chi$ are defined in Fig. 4. The rotation angle $\chi$ is related to the tilt angle, $\psi$, by:

$\cos \psi=\cos \chi \cdot \cos (\theta-\alpha)$

The information depth, $\tau_{\psi}^{h k l}$, is the diffraction-weighted average depth, $\left\langle z_{\psi}^{h k l}\right\rangle$ :

$$
\tau_{\psi}^{h k l}=\left\langle z_{\psi}^{h k l}\right\rangle=\frac{\int_{0}^{\infty} z \cdot e^{-\mu k_{\psi}^{h k l} z} \cdot d z}{\int_{0}^{\infty} e^{-\mu k_{\psi}^{h k l} z} \cdot d z}=\frac{1}{\mu k_{\psi}^{h k l}}
$$

For a layer of thickness, $t$, the information depth becomes:

$$
\tau_{\psi}^{h k l}=\left\langle z_{\psi}^{h k l}\right\rangle=\frac{\int_{0}^{t} z \cdot e^{-\mu k_{\psi}^{h k l} z} \cdot d z}{\int_{0}^{t} e^{-\mu k_{\psi}^{h k l} z} \cdot d z}=\frac{1}{\mu k_{\psi}^{h k l}}+\frac{t \cdot e^{-\mu k_{\psi}^{h k l} t}}{e^{-\mu k_{\psi}^{h k l} t}-1}
$$

Arbitrarily $\left\langle d_{\psi}^{h k l}\right\rangle$ could be, and often is, assigned to $\tau_{\psi}^{h k l}$. However, it can be straightforwardly demonstrated that such a relation between $\left\langle d_{\psi}^{h k l}\right\rangle$ and $\tau_{\psi}^{h k l}$ only applies if the lattice spacing depends linearly on depth [24]. Below the results obtained by asymmetric (grazing incidence) Xray diffraction are presented.

Asymmetric, grazing incidence diffraction geometry

The dependence of the lattice parameter, $\left\langle a_{\psi}^{h k l}\right\rangle$, as derived from the lattice spacings $\left\langle d_{\psi}^{111}\right\rangle$ and $\left\langle d_{\psi}^{200}\right\rangle$ (for the de-nitrided sample only $\left\langle d_{\psi}^{111}\right\rangle$ ) with the effective tilt angle (cf. Eq. (5)), $\psi$, in the asymmetric diffraction configuration is shown in Fig. 5a for the three applied grazing incidence 
angles. The corresponding information depths as calculated according to Eq. (6b) for average values of the Bragg angles corresponding with 111 and 200 reflections as well as for the actual combinations of experimental tilt and Bragg angles are presented in Fig. 5b. In the calculations the linear absorption coefficient of $\mathrm{Cr} \mathrm{K}_{\alpha}$ radiation in expanded austenite was taken as 0.0926 $\mu \mathrm{m}^{-1}$. The $\left\langle a_{\psi}^{h k l}\right\rangle$ vs. $\sin ^{2} \psi$ relations in Fig. 5a clearly demonstrate that for the as-nitrided sample strong compressive stresses are present, while for the subsequently de-nitrided sample the stresses have (largely) relaxed. The difference in slope for lattice parameters determined for 111 and 200 reflections shows that the lattice spacing measured in the $<200>$ direction is more sensitive for stress than those measured in the $<111>$ direction, implying that in Eq. (1) $1 / 2 S_{2}^{200}>1 / 2 S_{2}^{111}$, consistent with previous work $[8,25]$ and recently qualitatively explained from non-linear elastic behavior of plastically deformed expanded austenite [15]. The variation of the information depth with $\sin ^{2} \psi$ indicates that the lattice parameters in Fig. 5a are the effective average over different depth ranges and thus over different concentration ranges for the asnitrided sample (cf. Fig. 2). Consequently, stress values for the as-nitrided sample determined straightforwardly from the slopes of $\underline{\left\langle a_{\psi}^{111}\right\rangle} 111$ and $\underline{\left\langle a_{\psi}^{200}\right\rangle} z 00$ in Fig. 5a will be affected by a ghost stress artefact, i.e. fictitious stresses arising as a consequence of a variation with tilt angle of the effective depth where the measured lattice spacing applies and a lattice spacing profile as a consequence of a composition and/or a stress-depth profile (see also [8,24]). Ghost-stress effects arising from a composition-depth profile will be virtually absent for the de-nitrided sample, because here the composition appears independent of depth (Fig. 2); ghost stress effects arising from stress gradients only are generally limited [24] as was also shown for the case of expanded austenite zones [8]. Consistent with a variation of the information depth (Fig. 5b) with a 
variation in incident angle, and the falling nitrogen concentration with depth (Fig._2), the $\left\langle a_{\psi}^{h k l}\right\rangle$

vs. $\sin ^{2} \psi$ relations are shifted to lower $\left\langle a_{\psi}^{h k l}\right\rangle$ values with increasing grazing incidence angle, $\alpha$. For the de-nitrided sample, an important reduction in the slope and intercept of the $\left\langle a_{\psi}^{h k l}\right\rangle$ vs. $\sin ^{2} \psi$ relation is observed as compared to the nitrided sample. Now, consistent with the absence of a nitrogen concentration gradient within the probed volume (Fig. 2), the $\left\langle a_{\psi}^{111}\right\rangle$ values for the denitrided sample largely overlap for the three incident angles $3^{\circ}, 7^{\circ}$ and $12^{\circ}$. Even though the variation in information depth under grazing incidence diffraction conditions is limited (cf. Fig. 5b), the information depth at the highest tilt angle is $50 \%$ of that at the lowest tilt angle. As illustrated by the horizontal dashed line at $\tau_{\psi}=0.5 \mu \mathrm{m}$, a combination of the 3 applied grazing incidence angles, $\alpha$, and the appropriate effective tilt angles, $\psi$, enables to keep the information depth constant. Note that this does not guarantee that also the values for $\left\langle a_{\psi}^{h k l}\right\rangle$ apply at the same depth for the various $\psi$-directions, because such a correspondence is only expected for a linear lattice spacing profile [24]. The lattice parameters at $\tau_{\psi}=0.5 \mu \mathrm{m}$ as interpolated among the data in Fig. 5a for the chosen $\psi$ angles are given for 111 and 200 reflections in Fig. 6.

\section{Discussion}

\subsection{Residual stress and composition in expanded austenite}

From the relations between $\left\langle a_{\psi}^{h k l}\right\rangle$ and $\sin ^{2} \psi$ given in Figs. 5a and 6 the intercept, $\left\langle a_{\psi=0}\right\rangle$, and slope, $\Delta\left\langle a_{\psi}^{h k l}\right\rangle / \Delta \sin ^{2} \psi$, were obtained by linear regression. These values were applied to obtain 
the strain-free lattice parameter, $\left\langle a_{\varepsilon=0}\right\rangle$, nitrogen content, $y_{N}$, and residual stress, $\sigma_{\|}$. For this purpose (cf. Eqs. (1) and (2)), the X-ray elastic constants were taken as for $\mathrm{Fe}-12 \% \mathrm{Cr}-12 \% \mathrm{Ni}$ [26], applying the Kröner-Eshelby grain interaction model (see [8,24]). The nitrogen content was obtained from the relations between (strain-free) lattice parameter and interstitial content for nitrogen-stabilized and carbon-stabilized expanded austenite [27]. For the nitrided sample only the relation for nitrogen-stabilized expanded austenite is considered, while for the de-nitrided sample both relations were taken into account, recognizing the relation for nitrogen- and carbon stabilized expanded austenite represent ferro-magnetic and para-magnetic $\gamma_{\mathrm{N}}$, respectively [7]. For the nitrided and de-nitrided sample, all results obtained for $y_{N}$ (the occupancy of the lattice of octahedral interstices) and $\sigma_{\|}$are presented in Table 2. For the de-nitrided sample differentiation is made between para-magnetic $(\mathrm{pm})$ and ferro-magnetic $(\mathrm{fm})$ expanded austenite.

There appears to be a systematic discrepancy between $y_{N}$ values derived from the lattice parameters derived-obtained from 111 and 200 reflections, such that $y_{N}$ obtained from 200 is systematically higher (Fig. 7a). This is consistent with previous investigations, which showed that the 200 reflection is more sensitive than the 111 reflection for changes in composition/stress. As was pointed out the XECs in expanded austenite are unknown and likely depend on the nitrogen content in expanded austenite. Furthermore, analogous to austenite and as a consequence of elastic anisotropy, plastic deformation as occurring in the expanded austenite zone during its growth into austenite, will lead to $h k l$ dependent non-linear stress-strain behavior. In general in-plane equi-biaxial compression is comparable to out-of-plane uniaxial tension as the stress states differ by a hydrostatic pressure only. If effects of the free sample surface can be ignored, results for conventional mechanical uniaxial tension may therefore be used as reference 
to explain the different interactions along 111 and 200. As indicated by self-consistent elastoplastic models [18], 200 reflections along the tensile direction for a stainless steel comparable to the present exhibit more elastic strain than other reflections, which has also been experimentally confirmed to hold on average at the grain scale [28]. For 200 reflections perpendicular to the tensile axis, elasto-plastic simulations reveal much smaller elastic contractions than for other reflections, which is attributed to plastically anisotropic contraction of grains of certain orientations $[19,20]$. In the context of the present experiments, these results imply that the 200 reflection from elasto-plastically deformed samples deviates substantially from the purely elastic case. The 111 reflection is much less affected by the plastic response and is therefore the focus of the remainder of this paper. In agreement with experimental findings for elastic uniaxial tension [28], a grain interaction model (GIM) in-between the extremes of Reuss and Voigt is selected, in this case the Kröner-Eshelby elastic GIM. This does not necessarily imply that this combination of $h k l$ and GIM is preferred to obtain quantitatively correct stress values in expanded austenite, because so far the elastic constants remain unknown.

Comparison of the nitrogen contents derived from the strain free lattice parameter for 111 with the nitrogen content as determined with GD-OES (Fig. 2) shows very good correspondence for the nitrided sample, while for the de-nitrided sample good correspondence is obtained for the para-magnetic lattice dependence on interstitial content.

The stress values derived from lattice strains measured for 111 reflections and the KrönerEshelby GIM are presented in Fig. 7b as a function of the applicable information depth. For the nitrided sample the stresses obtained at 3 different grazing incidence angles increase with information depth. As followed from the $\left\langle a_{\psi}^{h k l}\right\rangle$ vs. $\sin ^{2} \psi$ graph in Fig.5a and $\mathrm{y}_{\mathrm{N}}$ in Fig.7a the 
nitrogen content in this region falls with depth giving rise to ghost stress effects, which would lead to an additional tensile stress value as compared to the actual stress. The additional tensile stress will be larger for a larger variation in information depth (cf. Fig. 5b). Hence, the compressive stress decreases with increasing information depth for the three grazing incidence angles. Indeed, correcting for the variation in information depth with tilt, by keeping the information depth constant, leads to a more negative stress value of about -5 GPa. For the 200 reflection the residual stress values are systematically less compressive than those obtained from the 111 reflection (Table 2) and, consistently with 111, a larger compressive stress value is obtained for a constant information depth. The lower compressive stress values for From the lattice strains probed for the (200) lattice planes as compared to the obtained stress values appear to be up to $15 \%$ smaller (in absolute value) than those derived from the lattice strain probed for the (111) lattice planes (Table 2) may indicate that stress relaxation occurs close to the surface. In this respect it is mentioned that the $h k l$ dependence of the XECs is unknown. Therefore this difference between stress derived from 111 and 200 reflections is considered a good correspondence.

For the de-nitrided sample compressive stress is observed to be largely independent of the grazing incidence angle. For the constant information depth of $0.5 \mu \mathrm{m}$ the de-nitrided sample yields virtually zero stress. The difference between stress values for constant grazing incidence angle and varying grazing incidence angle for constant information depth cannot be explained from a concentration gradient (cf. Fig. 2). 


\subsection{Implications for industrial application}

The present results show that an expanded austenite zone in its as-grown state has huge compressive elastic residual stresses which are largely composition-induced, consistent with previous investigations. Upon de-nitriding these elastic stresses relax to a virtually unstressed state, despite the presence of a substantial amount of nitrogen in the expanded austenite zone. The reason for elastic relaxation of the compressive residual stresses in the expanded austenite zone after de-nitriding is that an appreciable part of the lattice expansion associated with nitrogen dissolution is accommodated plastically during growth of the expanded austenite zone into the original austenite. The observed splitting of the 200 peak of the de-nitrided sample is evidence of the complexity of this relaxation.

Nitriding at a low nitriding potential to achieve the relatively low nitrogen content as obtained after de-nitriding (cf. Fig. 2) is anticipated to give an expanded austenite case different from the one achieved here by nitriding and subsequent de-nitriding. Firstly, the growth rate will be reduced importantly, due the smaller diffusive flux as a consequence of the shallower concentration profile and the smaller (concentration dependent) diffusion coefficient of nitrogen (cf. $[9,10,27])$. Secondly, the extent of plastic deformation in expanded austenite will be limited [10]. Nevertheless, the level of elastic residual stress (close to the surface) will be high, because the elastic accommodation of the lattice expansion is still present.

The notion that elastic compressive stresses can be released by removing nitrogen from solid solution implies that the level of elastic residual stress in expanded austenite can in principle be adjusted after growth of the case, by inserting the appropriate level of dissolved nitrogen in a controlled atmosphere with known nitrogen activity in the final stage of the thermochemical 
treatment. Such after-treatment can also be of practical use for adjusting magnetic properties, because the de-nitrided condition is paramagnetic. Reducing the nitrogen content to below the threshold level ( $\mathrm{y}_{\underline{N}}=0.17$ ) where expanded austenite becomes ferro-magnetic can be beneficial. For example, in components where wear plays a role, so that no debris is accumulated, because of magnetic attraction.

\section{Conclusions}

The present work demonstrates that the choice of $h k l$ for residual stress analysis in expanded austenite is of paramount importance. The 200 line profile is not a good choice for the elastically and plastically anisotropic expanded austenite with remaining plastic deformation.

Even for the shallow information depths obtained by grazing incidence X-ray diffraction ghost stress effects in a (steep) lattice parameter profile, arising from a variation of information depth with tilt angle may play a role of importance. A combination of grazing incidence angles to keep the information depth constant with tilt angle appears to be a pragmatic solution.

De-nitriding of expanded austenite can be applied to vary the nitrogen content in the expanded austenite zone and tune the residual stress level at the surface. De-nitriding has a modest effect on the hardness profile.

\section{Acknowledgement}

Frederico A.P. Fernandes is grateful to the CNPq Brazilian council for the scholarship granted under the process number 201858/2011-8. 


\section{References}

[1] M.A.J. Somers, T.L. Christiansen, in Thermochemical Surface Engineering, WoodHead Publishing, ISBN 978-0-85709-592-3, 2015, 555-579.

[2] B. Kolster, VDI-Berichte 506 (1983) 107-113.

[3] L.Z. Zhang, T. Bell, Surf. Eng. 1 (1985) 131-136.

[4] M.P. Fewell, D.R.G. Mitchell, J.M. Priest, K.T. Short, G.A. Collins, Surf. Coatings Techn. 131 (2000) 300-306.

[5] R.L.O Basso, V.L. Pimentel, S. Weber, G. Marcos, T. Czerwiec, I.J.R. Baumvol, C.A. Figueroa, J. Appl. Phys, 105 (2009) 124914

[6] B. Brink, K. Ståhl, T.L. Christiansen, M.A.J. Somers, J. Appl. Cryst., 47 [2014), 819-826.

[7] B.K. Brink, K. Ståhl, T.L. Christiansen, C. Frandsen, M.F. Hansen, M.A.J. Somers, Acta Mater., 106, 2016, 32-39.

[8] F.A.P. Fernandes, T.L. Christiansen, G. Winther, M.A.J. Somers, Acta Mater. 94 (2015) 271-280.

[9] T.L. Christiansen, K.V. Dahl, M.A.J. Somers, Mater. Sci. Techn. 24 (2008) 159-167.

[10] F.N. Jespersen, J.H. Hattel, M.A.J. Somers, Model. Sim. Mater. Sci. Eng. 24 (2016) 025003 (31p)

[11]H. He, T. Czerwiec, C.Dong, H. Michel, Surf. Coatings Techn. 163-164 (2003) 331-338.

[12] A. Martinavičius, G. Abrasonis, W. Möller, J. Appl. Phys. 110 (2011) 074907.

[13]D. Wu, H. Kahn, J.C. Dalton, G.M. Michal, F. Ernst, A.H. Heuer, Acta Mater. 79 (2014) 339-350.

[14]C. Templier, J.C. Stinville, P. Villechaisse, P.O. Renault, G. Abrasonis, J.P. Rivière, A. Martinavičius, M. Drouet, Surf. Coatings Techn. 204 (2010) 2551-2558. 
[15]B.K. Brink, K. Ståhl, T.L. Christiansen, J. Oddershede, G. Winther, M.A.J. Somers, Scr. Mater. 117 (2017) 59-62.

[16] S. Baunack, V. Hoffmann, W. Zahn, Microchim. Acta, 156 (2006) 69-72.

[17] J.C. Stinville, C. Templier, P. Villlechaisse, L. Pichon, J. Mater. Sci. 46 (2011) 5503-5511.

[18] J. Oddershede, T.L. Christiansen, K. Ståhl, M.A.J. Somers, Scr. Mater. 62 (2010) 290-293.

[19]B. Clausen, T. Lorentzen, T. Leffers, Acta Mater. 46 (1998) 3087-3098.

[20] D.-F. Li, N.P. O’Dowd, J. Mech. Phys. Solids 59 (2011) 2421-2441.

[21] V. Hauk, “Structural and Residual Stress Analysis by Non-Destructive Methods: Evaluation - Application - Assessment”, Elsevier Science, 1997.

[22] A. Pyzalla, H. Berns, Mat.-wiss. U. Werkstofftech. 24 (1997) 180-197.

[23] P.J. Withers, H.K.D.H. Bhadeshia, Mater. Sci. Tech., 17 (2001) 355-365.

[24] T.L. Christiansen, M.A.J. Somers, Mater. Sci. Eng. A, 424 (2006) 181-189.

[25]F. Bottoli, T.L. Christiansen, G. Winther, M.A.J. Somers, Metall. Mater. Trans. A, 47 (2016) 4001-4011.

[26]F. Bollenrath, V. Hauk, E. Müller, Z. Metallkd. 58 (1967) 76-82.

[27] T.L. Christiansen, M.A.J. Somers, Int. J. Mater. Res. Former. Zeitschrift Fuer Met. 100 (2009) 1361-1377.

[28] N.Y. Juul, G. Winther, D. Dale, M.K.A. Koker, P. Shade, J. Oddershede, Scr. Mater., 120 (2016) 1-4. 
Figure 1 - Cross sectional reflected-light micrographs (a,b) and microhardness-depth profiles (c): (a) as nitrided and (b) after de-nitriding.

Figure 2 - Nitrogen occupancy, $\mathrm{y}_{\mathrm{N}}$, versus depth, $\mathrm{z}$, for the as-nitrided (GN) and de-nitrided (GN+DN) AISI 316L samples obtained by GD-OES.

Figure 3 - X-ray diffraction patterns of AISI 316L un-nitrided (line), nitrided (black circles) at $713 \mathrm{~K}$ $\left(440^{\circ} \mathrm{C}\right)$ and subsequently de-nitrided (grey triangles) at $708 \mathrm{~K}\left(435^{\circ} \mathrm{C}\right)$.

Figure 4- Definition of grazing incidence angle $\alpha$, Bragg angle $2 \theta$ and rotation angle $\chi$ for lattice strain determination with asymmetric geometry.

Fig. 5- Dependence of lattice parameter, $\left\langle a_{\psi}^{h k l}\right\rangle$, versus the tilt angle, $\psi$, in asymmetric diffraction condition at three incident angles $\alpha$, for nitrided and de-nitrided samples (a.) and dependence of information depth $\tau_{\psi}$ on $\sin ^{2} \psi$ for the Bragg angles of 111 and 200 reflections for grazing incidence angles, $\alpha$ (b.). The drawn and dash-dot lines in (b.) were calculated for an infinitely thick substrate (which is inseparable from the results for a finite layer of $14 \mu \mathrm{m}$ ) for average Bragg positions for 111 and 200. The markers refer to the actual experimental values of effective tilt and Bragg angle applying (Eq. 6b). 
Fig. 6- Comparison of $\left\langle a_{\psi}^{h k l}\right\rangle$ vs. $\sin ^{2} \psi$ for constant $\tau_{\psi}$ diffraction conditions.

Fig. 7- Nitrogen content expressed as the occupancy of the lattice of octahedral interstices, $y_{N}$, (a.) and residual stress, $\sigma_{\square}$, (b.) as determined for the straight lines in Fig. 5a, and 6 and presented vs. the information depth $\tau$. The $\mathrm{X}$-ray elastic constants were taken as for $\mathrm{Fe}-12 \% \mathrm{Cr}-12 \% \mathrm{Ni}$, applying the Kröner-Eshelby grain interaction model. Residual stress values are only given for lattice strains determined from the 111 reflection, because the elastic constants for 111 are insensitive for plastic deformation as compared to 200 . 
Figure $1 \mathrm{ab}$
Click here to download high resolution image
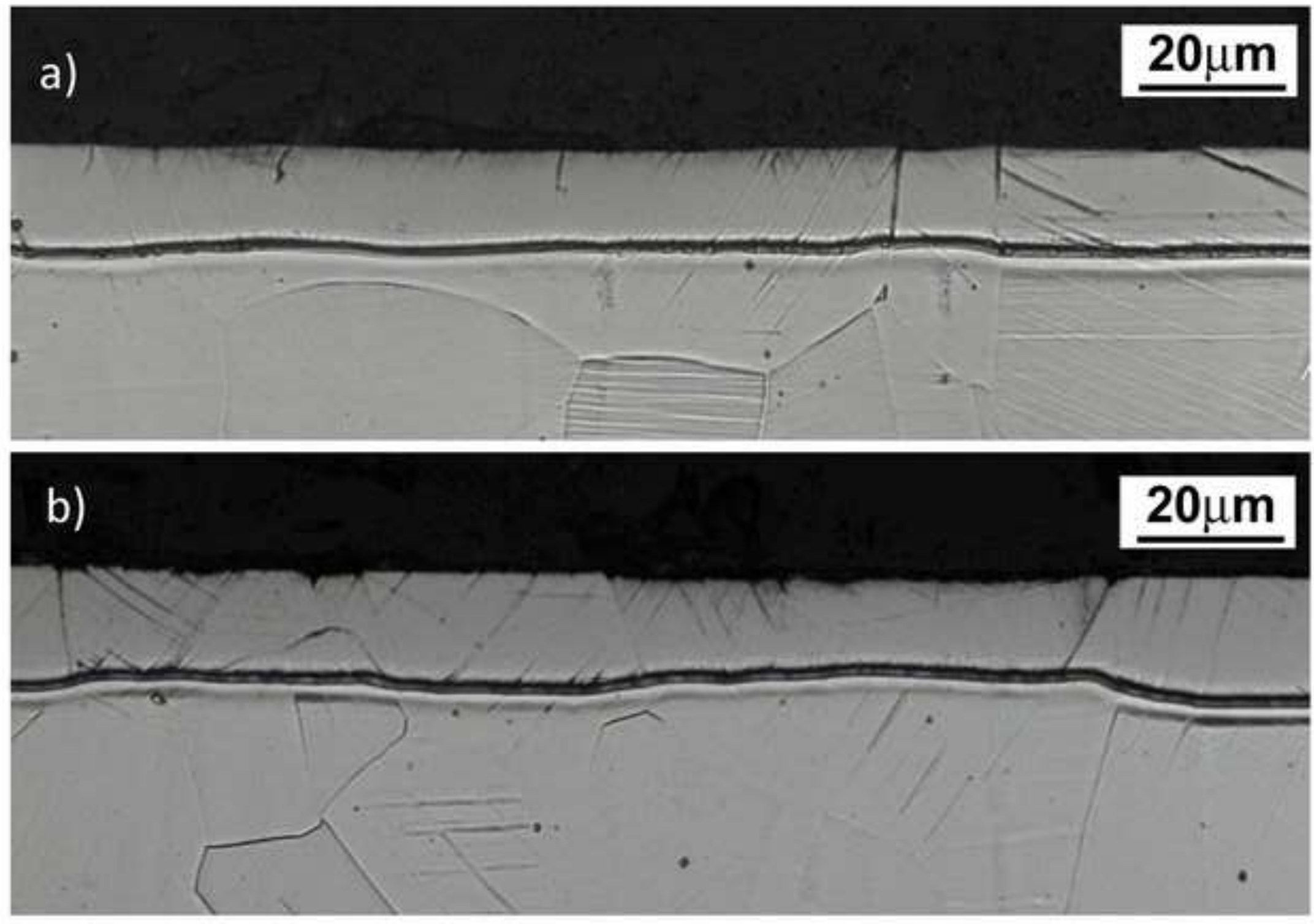


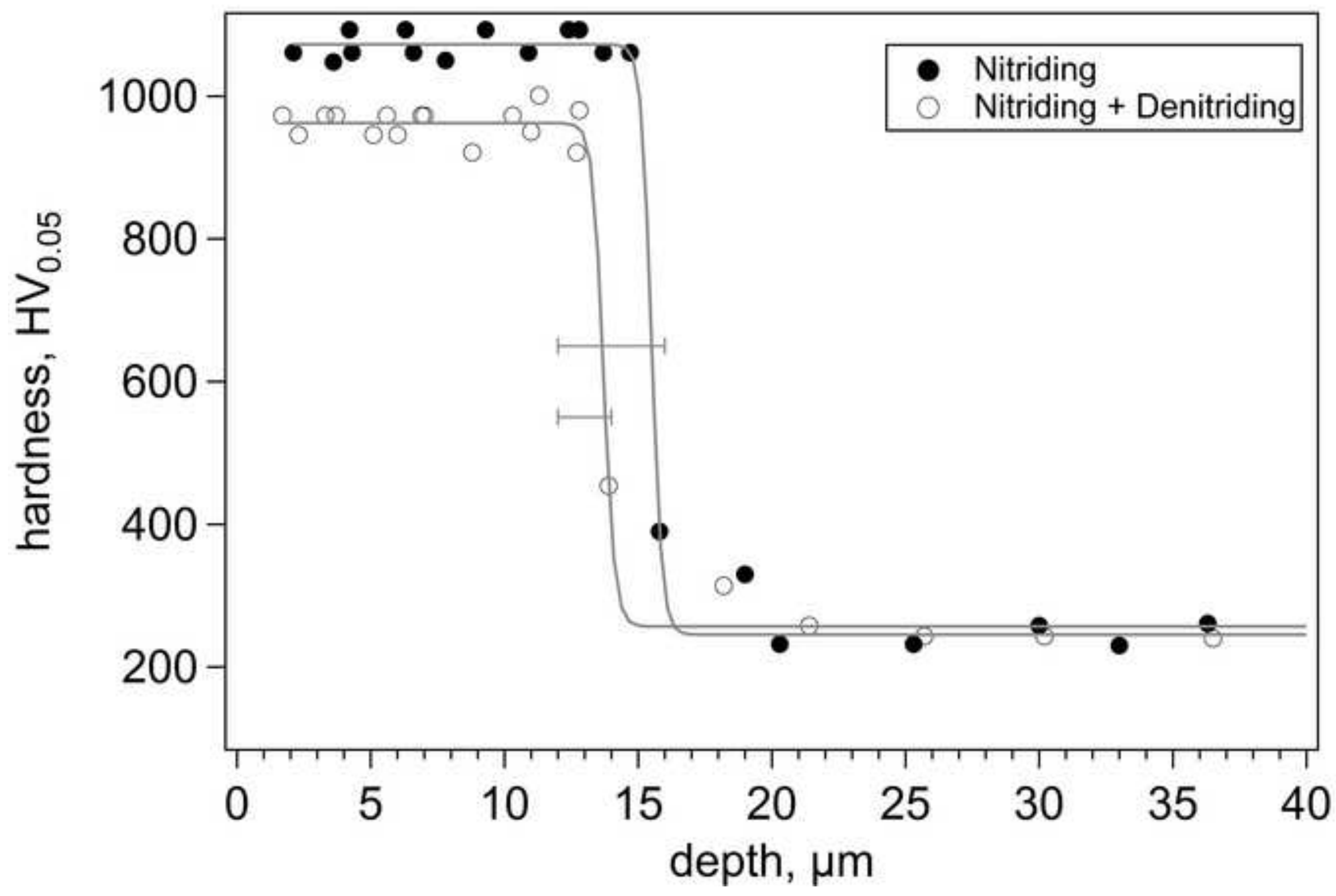




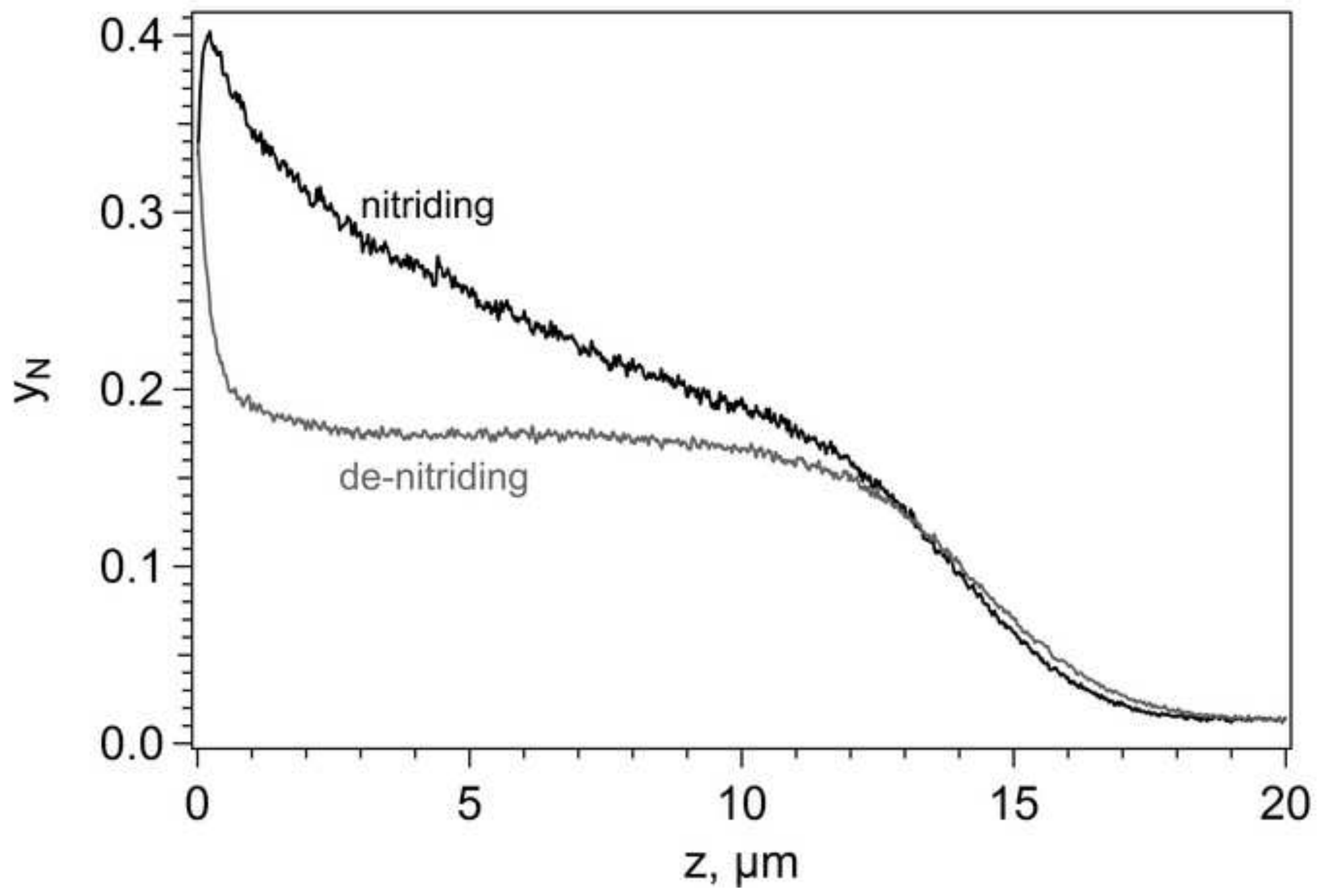




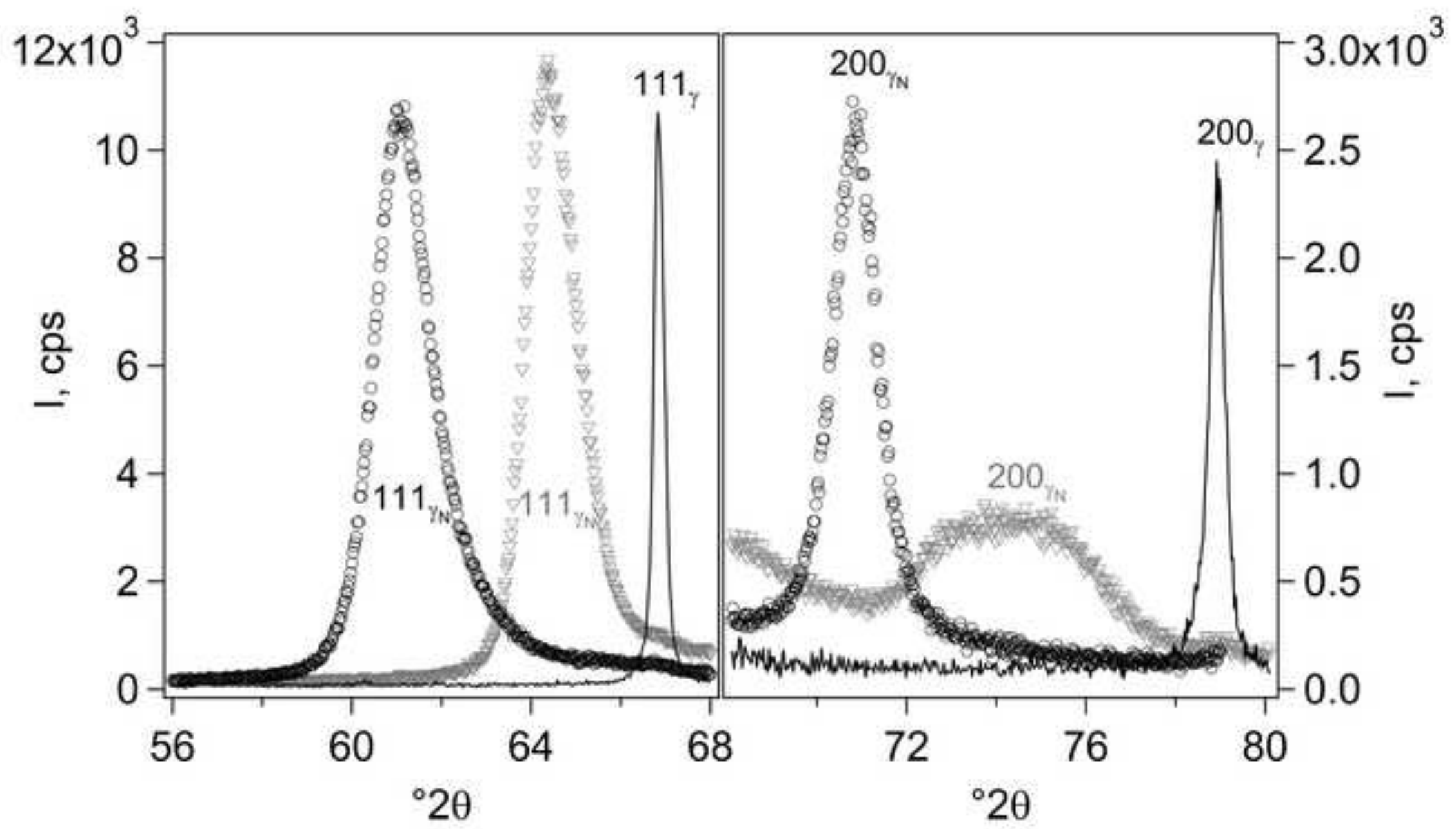




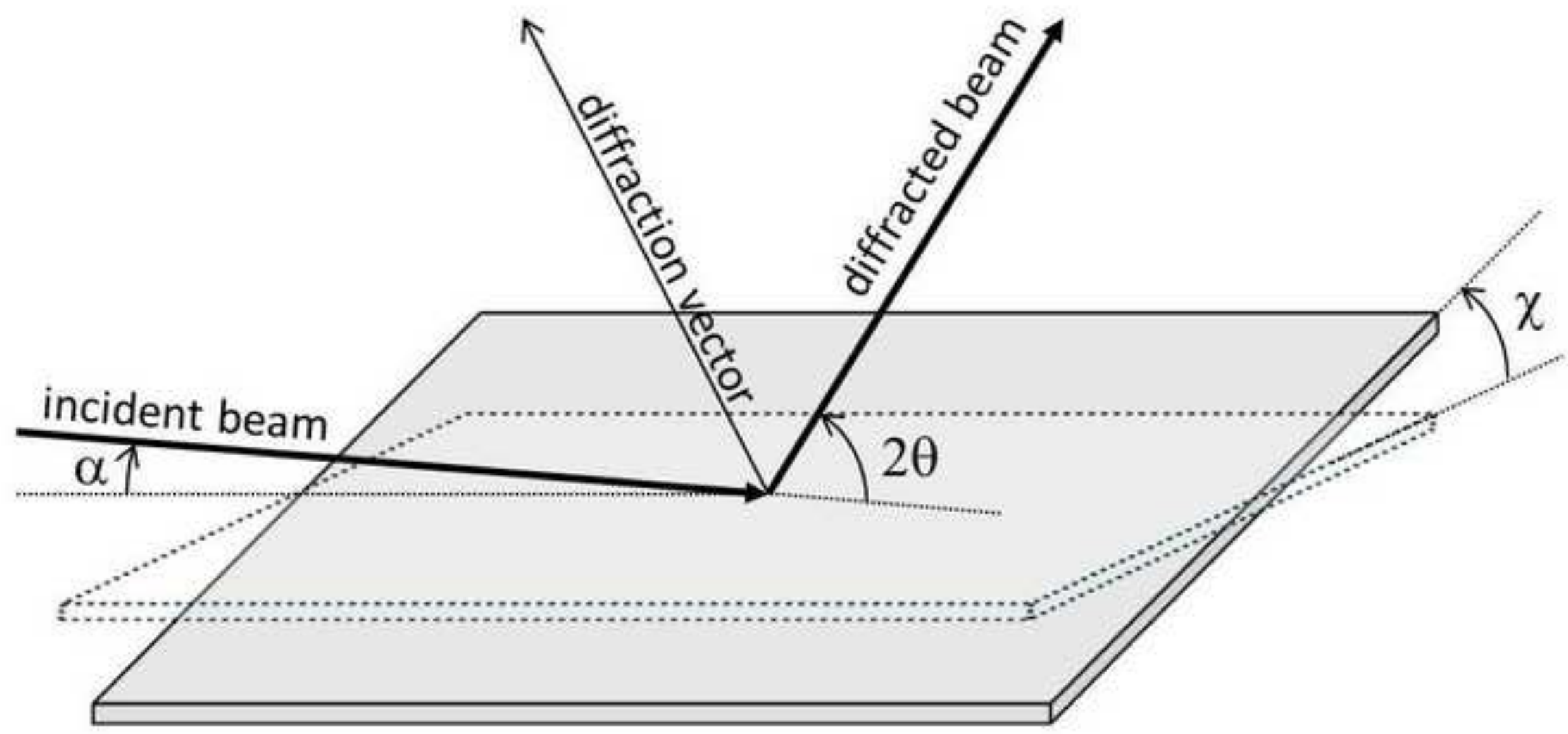


Figure $5 \mathrm{a}$
Click here to download high resolution image

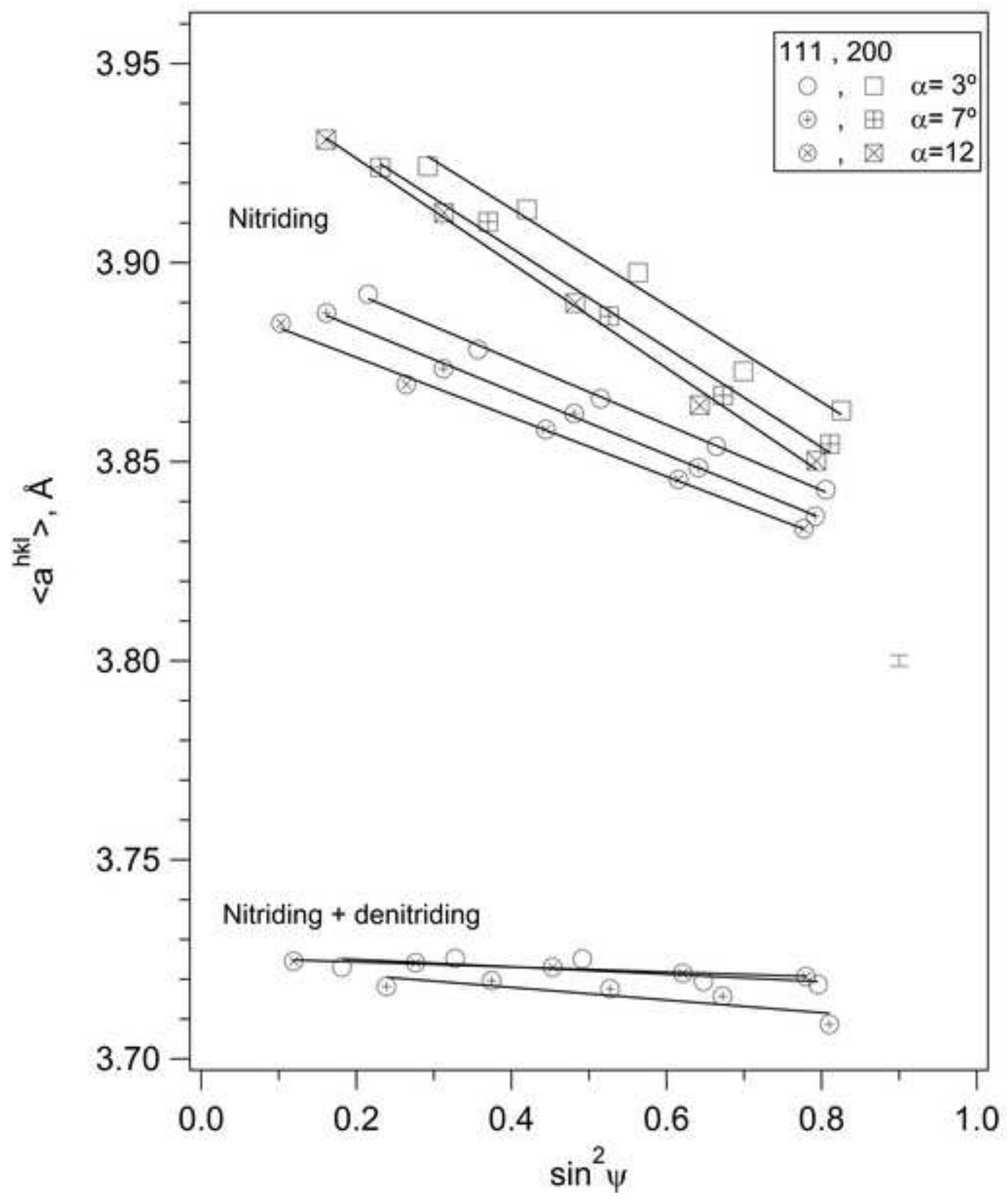




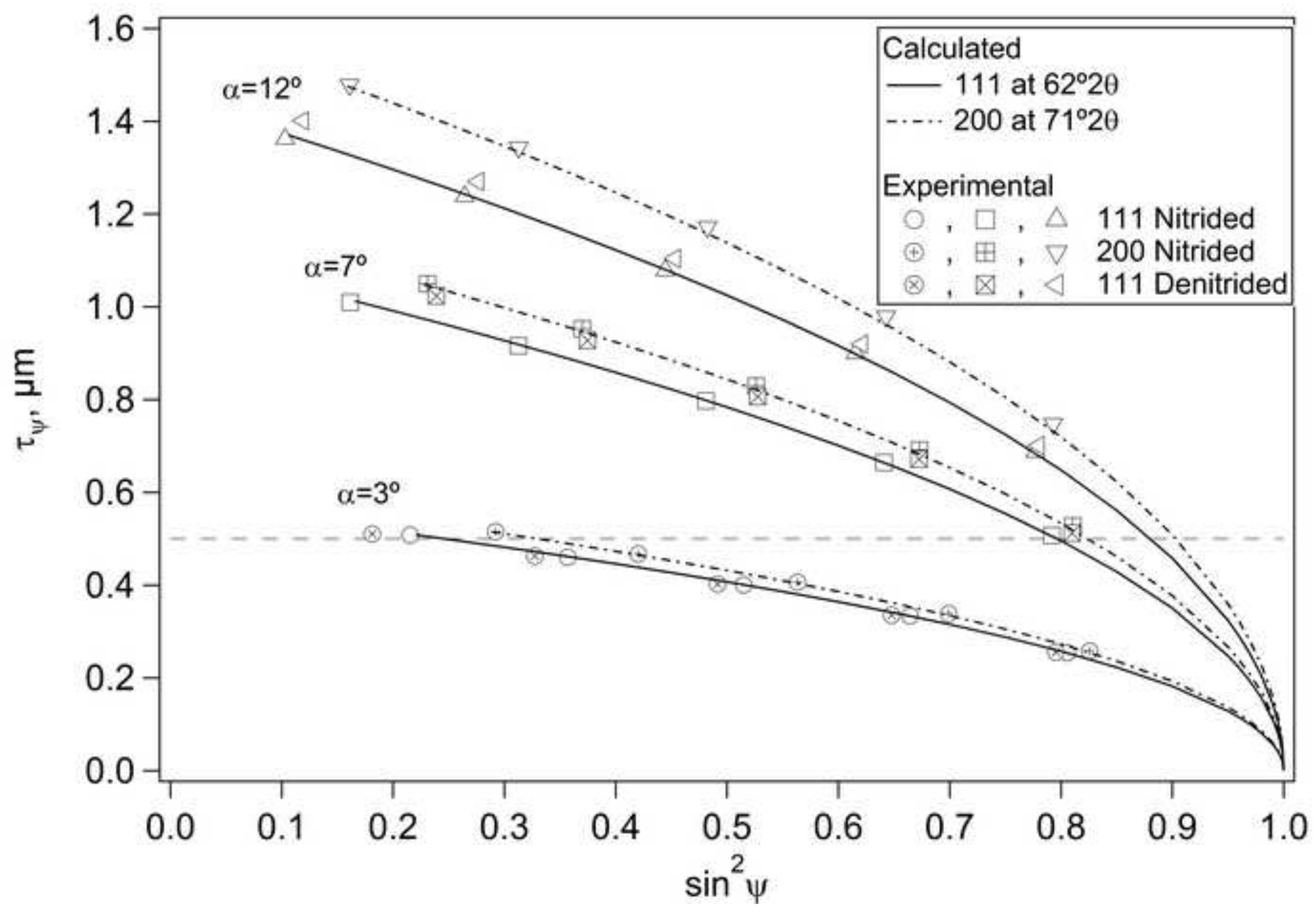


Click here to download high resolution image

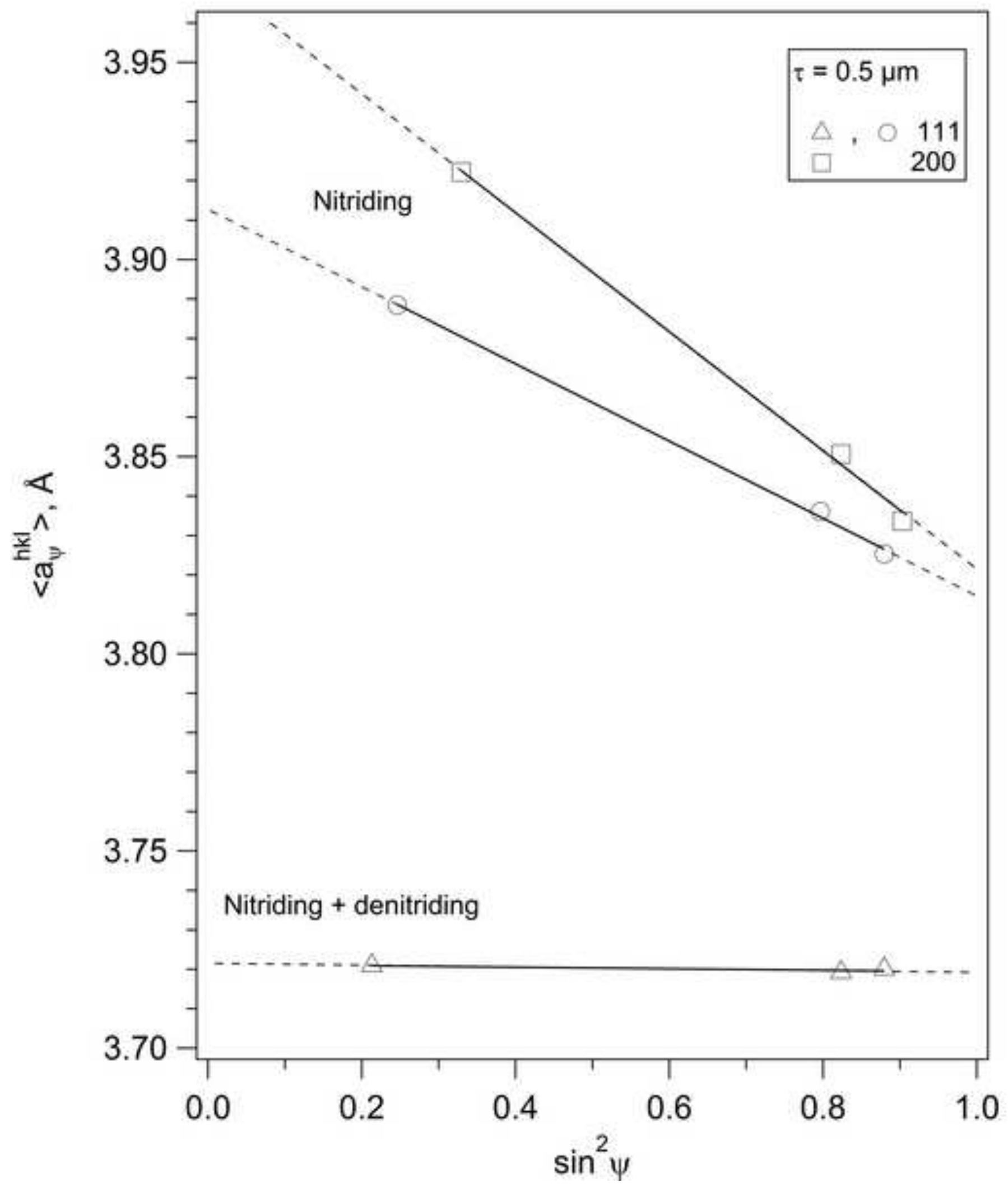




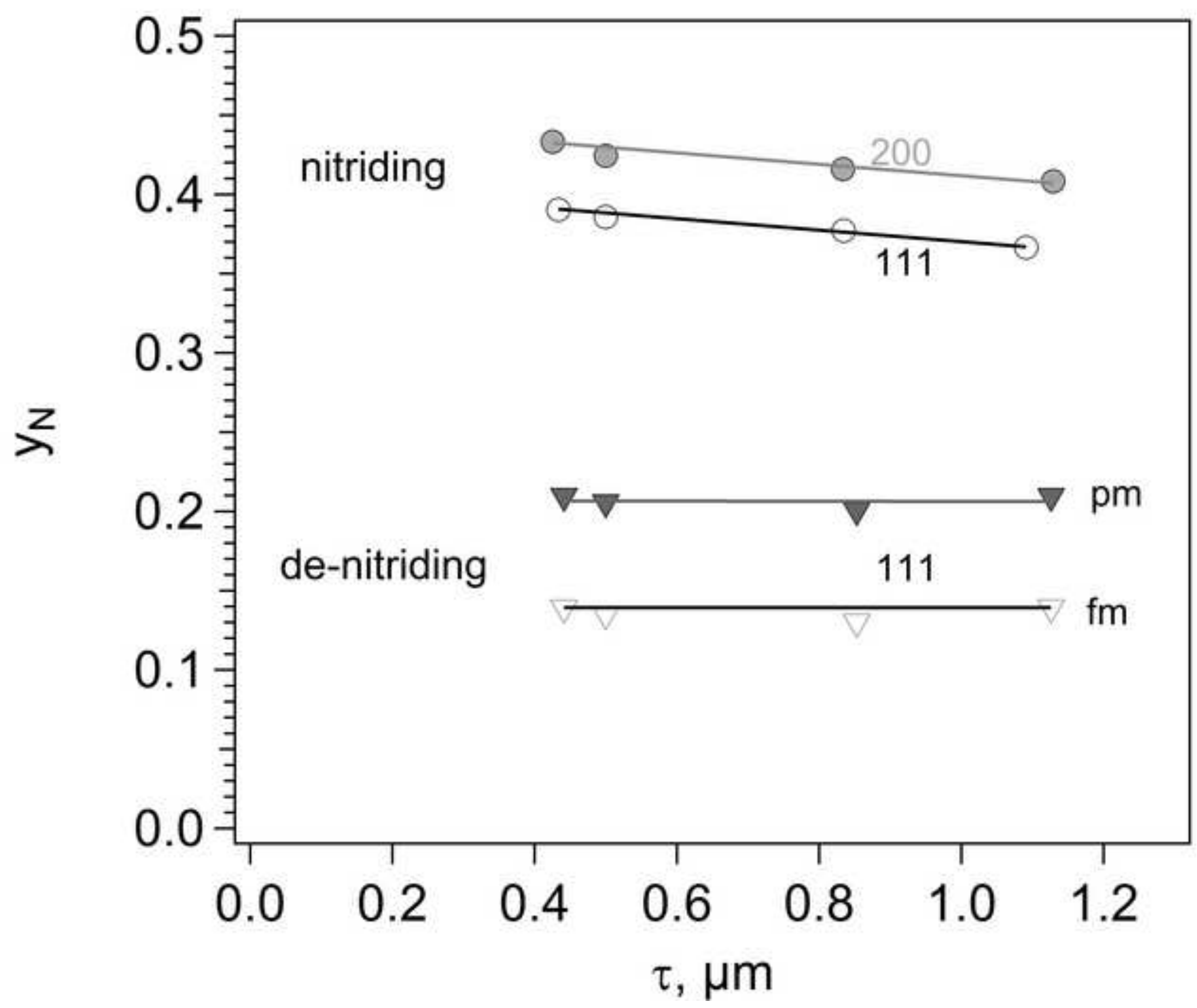


Figure
Click here to download high resolution image

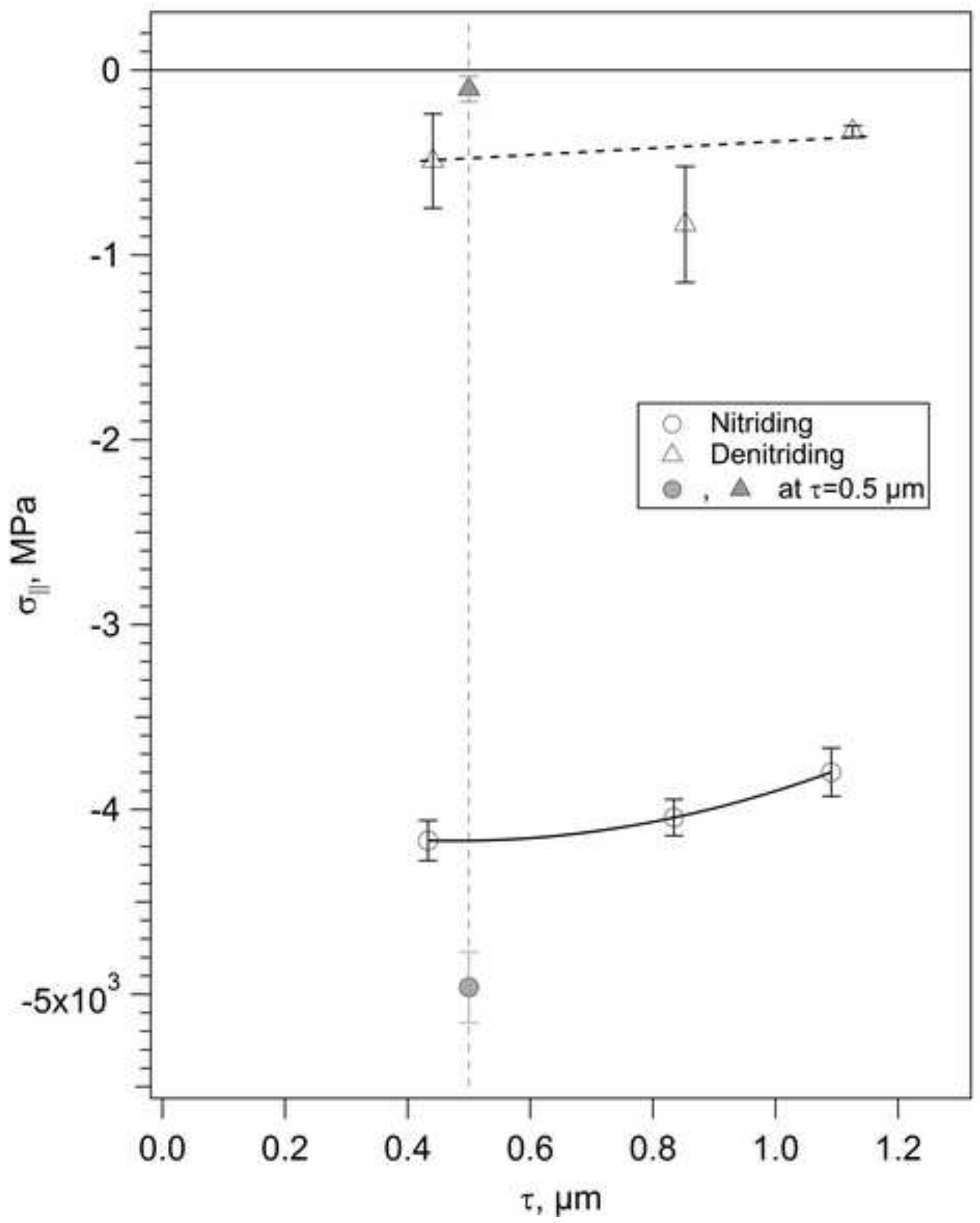


Table 1 - Chemical composition in wt-\% of the studied AISI 316L alloy.

\begin{tabular}{cccccccccc}
\hline & $\mathbf{C}$ & $\mathbf{N}$ & $\mathbf{M n}$ & $\mathbf{S i}$ & $\mathbf{C r}$ & $\mathbf{N i}$ & $\mathrm{Mo}$ & $\mathbf{C u}$ & $\mathbf{F e}$ \\
\hline AISI 316L & 0.019 & 0.067 & 1.47 & 0.40 & 16.26 & 10.05 & 2.02 & 0.47 & bal. \\
\hline
\end{tabular}


Table 2

Intercept, $\left\langle a_{\psi=0}\right\rangle$, slope, $\Delta\left\langle a_{\psi}^{h k l}\right\rangle / \Delta \sin ^{2} \psi$, strain-free lattice parameter, $\left\langle a_{\varepsilon=0}\right\rangle$, nitrogen content, $y_{N}$, and residual stress, $\sigma_{\square}$, as determined for the straight lines in Fig. 5a and 6. The X-ray lattice parameters were taken as for $\mathrm{Fe}-12 \% \mathrm{Cr}-12 \% \mathrm{Ni}$ [26], applying the Kröner-Eshelby grain interaction model, yielding: $S_{1}^{111}=-1.110^{-6} \mathrm{MPa}^{-1}, S_{1}^{200}=-2.310^{-6} \mathrm{MPa}^{-1}, 1 / 2 S_{2}^{111}=5.110^{-6} \mathrm{MPa}^{-1}, 1 / 2 S_{2}^{200}=8.83$ $10^{-6} \mathrm{MPa}^{-1}$. For the de-nitrided sample $\mathrm{fm}$ and $\mathrm{pm}$ refer to ferro-magnetic and para-magnetic expanded austenite, respectively.

\begin{tabular}{|c|c|c|c|c|c|c|c|}
\hline sample & hkl & $\alpha,^{\circ}$ & $\begin{array}{c}\left\langle a_{\psi=0}\right\rangle, \\
\AA\end{array}$ & $\left\langle a_{\psi}^{h k l}\right\rangle /{ }_{\Delta \sin ^{2}}$ & $\begin{array}{l}\left\langle a_{\varepsilon=0}\right\rangle, \\
\AA\end{array}$ & $y_{N}$ & $\begin{array}{l}\sigma_{\square}, \\
\mathrm{MPa}\end{array}$ \\
\hline \multirow[t]{8}{*}{ Nitrided } & \multirow[t]{4}{*}{111} & 3 & 3.9087 & -0.082341 & 3.8732 & 0.3903 & -4168 \\
\hline & & 7 & 3.8996 & -0.079717 & 3.8652 & 0.3770 & -4044 \\
\hline & & 12 & 3.8911 & -0.074738 & 3.8589 & 0.3664 & -3798 \\
\hline & & $\tau=0.5 \mu$ & 3.9127 & -0.097946 & 3.8704 & 0.3858 & -4962 \\
\hline & \multirow[t]{4}{*}{200} & 3 & 3.9622 & -0.12157 & 3.8989 & 0.4332 & -3531 \\
\hline & & 7 & 3.9537 & -0.12514 & 3.8885 & 0.4159 & -3645 \\
\hline & & 12 & 3.9525 & -0.13165 & 3.8839 & 0.4082 & -3839 \\
\hline & & $\tau=0.5 \mu$ & 3.9722 & -0.15095 & 3.8936 & 0.4244 & -4391 \\
\hline \multirow[t]{2}{*}{$\begin{array}{l}\text { De- } \\
\text { nitrided }\end{array}$} & \multirow[t]{2}{*}{111} & 3 & 3.7243 & -0.015847 & 3.7175 & $\begin{array}{l}0.1302(\mathrm{fm}) \\
0.2096(\mathrm{pm})\end{array}$ & -835 \\
\hline & & 7 & 3.7269 & -0.009359 & 3.7229 & $\begin{array}{l}0.1393(\mathrm{fm}) \\
0.2006(\mathrm{pm})\end{array}$ & -492 \\
\hline
\end{tabular}




\begin{tabular}{|l|c|c|c|c|c|c|c|}
\hline \multirow{2}{*}{} & 12 & 3.7256 & -0.006312 & 3.7229 & $0.1393(\mathrm{fm})$ & -332 \\
& & & & & $0.2097(\mathrm{pm})$ & \\
\cline { 3 - 8 } & & & & & & & \\
\hline
\end{tabular}

